(A) Check for updates

Cite this: Org. Biomol. Chem., 2021, 19, 3159

Received 18th January 2021 Accepted 14th March 2021

DOI: 10.1039/d1ob00088h rsc.li/obc

\title{
Metal-templated synthesis of rigid and conformationally restricted cyclic bisporphyrins: specific retention times on a cyanopropyl- modified silica gel column $\uparrow$
}

\author{
Masaya Hashimoto, ${ }^{a}$ Yusuke Kuramochi, (D) a,b Sayumi Ito, ${ }^{\text {b }}$ Yuho Kinbara ${ }^{a}$ and \\ Akiharu Satake iD *a,b
}

\begin{abstract}
A series of rigid and conformationally restricted cyclic bis(zinc porphyrin)s connected via 2,2'-bipyridine and phthalamide, isophthalamide, or terephthalamide moieties were prepared by metal-templated synthesis. The yields were significantly improved when compared with those obtained under metal-free conditions. In particular, phthalamide and terephthalamide derivatives were obtained only by metal-templated synthesis. Structural analyses and dynamics of the exchange between the conformers in each cyclic porphyrin were examined by NMR spectroscopy. Although the distances between the two zinc porphyrins were extended in the order of phthalamide, isophthalamide, and terephthalamide derivatives, the order of the specific retention of the cyclic porphyrins on cyanopropyl-modified silica gel (CN-MS) chromatography columns varied. Thus, this order was reversed in the isophthalamide and terephthalamide derivatives. Based on the rigid structure of the terephthalamide derivative, the origin of the specific retention on the CN-MS chromatography column was attributed to both the distance and rigidity of the cyclic porphyrins.
\end{abstract}

\section{Introduction}

Cofacial bis(metalloporphyrin) derivatives are known as molecule-based functional materials. The functionalities are spread over various areas, such as chiral sensing, ${ }^{1,2}$ molecular recognition, ${ }^{3}$ supramolecular polymers, ${ }^{4}$ oxygen activation, ${ }^{5,6}$ and catalysts. $^{6-8}$ Because their functions are related to the distances and dihedral angles between the two porphyrins as well as conformational freedom, the preparation of various cofacial bis(metalloporphyrin)s has been beneficial. ${ }^{9-11}$ Previously, we reported the synthesis of bis(zinc porphyrin)s connected through 2,2'-bipyridyl at 4,4'-positions. Their conformations were controlled to the cofacial orientation by complexation with metal ions on the 2,2'-bipyridyl moieties. ${ }^{12,13}$

Herein, we report the synthesis of a series of bis(zinc porphyrin)s connected through 2,2'-bipyridyl at 6,6'-positions, followed by covalent linkage of the opposite meso-positions of the

${ }^{a}$ Department of Chemistry, Graduate School of Science, Tokyo University of Science, 1-3 Kagurazaka, Shinjuku-ku, Tokyo 162-8601, Japan. E-mail: asatake@rs.tus.ac.jp ${ }^{b}$ Department of Chemistry, Faculty of Science Division II, Tokyo University of Science, Japan

$\dagger$ Electronic supplementary information (ESI) available: NMR spectra of $\mathbf{4 Z n}$, $\mathbf{5 F b} \mathbf{b}_{2}, \mathbf{6 F b} \mathbf{b}_{2}, \mathbf{7 F b}, \mathbf{8} \mathbf{F b}_{2}, \mathbf{Z n}_{2}-\mathbf{C P} 2_{m}$, and $\mathbf{Z n}-\mathbf{C P} 2_{p}$. See DOI: $10.1039 / \mathrm{d} 1 \mathrm{ob} 00088 \mathrm{~h}$ bis(zinc porphyrin)s. Thus, the two porphyrins are connected to different positions of a 2,2'-bipyridyl moiety by comparing them with the previous ones, and subsequently fixing them. These compounds are designed for different purposes from the previous one. The conceptual molecular structure of this project is shown in Fig. 1A. Here, a 2,2'-bipyridyl moiety is connected to the 6 and $6^{\prime}$-positions at the meso-position of two

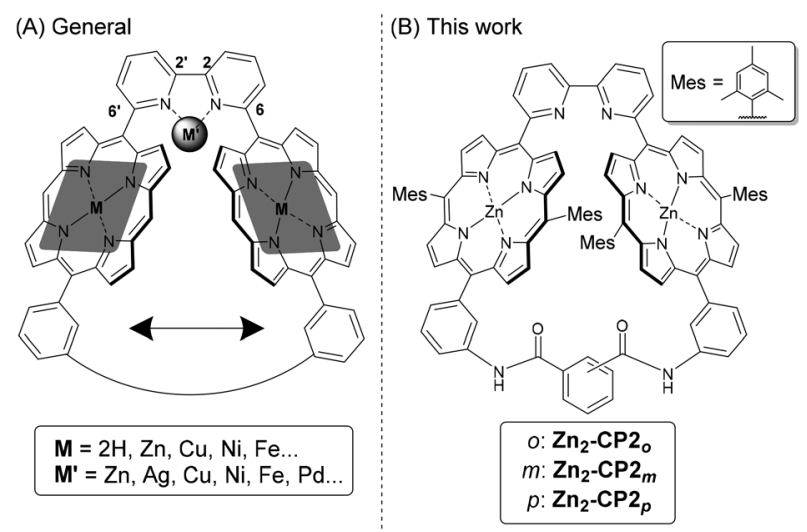

Fig. 1 (A) A conceptual molecular structure of cofacial cyclic bisporphyrin. (B) Structures of cofacial cyclic bisporphyrins $\left(\mathrm{Zn}_{2}-\mathrm{CP} \mathbf{2}_{o, m, p}\right)$. 
metalloporphyrins, which are linked via an appropriate linker at the opposite meso-positions. The introduction of appropriate linkers regulates the distances and dihedral angles between the two metalloporphyrins, as well as their conformational freedom. In the linked bismetalloporphyrin, the association constants of metal ions on the 2,2'-bipyridyl moiety increase because the conformational freedom of the bipyridyl moiety is significantly decreased by the linkage. This is advantageous for assessing various metal ions with the 2,2'bipyridyl moiety. In addition, an unusual orientation of metal complexes or organometallic complexes is expected on such a spatially restricted ligand. ${ }^{14}$ In porphyrin moieties, various metal ions can also be introduced to systematically afford various functional multinuclear complexes. For instance, Mn, $\mathrm{Fe}, \mathrm{Co}, \mathrm{Ru}$, and $\mathrm{Rh}$ porphyrins act as photoredox catalysts for olefin epoxidation, ${ }^{15,16} \mathrm{CO}_{2}$ reduction, ${ }^{17-19}$ oxidation of hydrocarbons, ${ }^{20,21}$ water oxidation, ${ }^{22}$ syntheses of $N$-acyl sulfimides and sulfoximines, ${ }^{23}$ and carbon-carbon $\sigma$-bond oxidation. $^{24}$ Zinc porphyrin acts as a photosensitizer in photochemical reactions, for example, photoinduced $\alpha$-functionalization of aldehydes, ${ }^{25}$ photoinduced living polymerization, ${ }^{26}$ light-driven $\mathrm{O}_{2}$ reduction, ${ }^{27}$ and photocatalytic $\mathrm{CO}_{2}$ reduction. ${ }^{28,29}$ Thus, because the bismetalloporphyrin, as shown in Fig. 1A, has a coordination site by the 2,2'bipyridyl part inside the restricted space, a systematic introduction of metal ions on the 2,2'-bipyridyl part will be beneficial for improving their catalytic activities or inducing successive catalytic reactions.

The particular molecular structures described in this paper are shown in Fig. 1B. We planned to synthesize a series of bis (zinc porphyrin) derivatives, $\mathbf{Z n}_{2}-\mathbf{C P} \mathbf{2}_{\boldsymbol{o}}, \mathbf{Z n}_{\mathbf{2}}-\mathbf{C P} \mathbf{2}_{\boldsymbol{m}}$, and $\mathbf{Z n}_{\mathbf{2}^{-}}$ $\mathbf{C P}_{\boldsymbol{p}}$, in which the two porphyrins are connected via phthalamide, isophthalamide, and terephthalamide, respectively. Among the bisporphyrin derivatives, the distances and dihedral angles between the two porphyrin moieties varied systematically. Previously, we reported the specific and efficient chromatographic isolation of cofacial cyclic trisporphyins from mixtures containing similar linear porphyrin derivatives on functionalized silica gel. ${ }^{32}$ Indeed, this chromatography was useful for isolating cyclic bisporphyrin derivatives, even though they exist as minor products in crude mixtures. Another purpose of this work was to understand the principle of unique chromatographic behavior. The preparation of a series of similar bisporphyrins is useful for discussing the relationships between structures and retention behaviors on functionalized silica gels.

In this paper, we report the preparation of cofacial bispor-

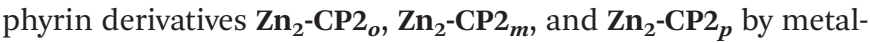
templated macrocyclic formation followed by their efficient separation on cyanopropyl-modified silica gel (CN-MS). In the subsequent sections, the structural analyses and dynamics of the conformational changes of the bisporphyrin derivatives are described. Finally, a new insight into the origin of the specific retentions is discussed based on the relationships between retention behaviors and structural factors of a series of cyclic bisporphyrin derivatives.

\section{Results and discussion}

Two synthetic routes were considered for the synthesis of $\mathbf{Z n}_{2}$ $\mathbf{C P} 2_{\boldsymbol{o}, \boldsymbol{m}, \boldsymbol{p}}$, as shown in Scheme 1 . In the first route $(\mathbf{A} \rightarrow \mathbf{B} \rightarrow \mathbf{D})$, nickel-mediated homocoupling is applied to produce $\mathbf{B}$, followed by cross-linking with phthalic, isophthalic, or terephthalic dichloride to produce $\mathbf{Z} \mathbf{n}_{\mathbf{2}}-\mathbf{C P} \mathbf{2}_{\boldsymbol{o}, \boldsymbol{m}, \boldsymbol{p}}$ (D), respectively. In the other route $(\mathbf{A} \rightarrow \mathbf{C} \rightarrow \mathbf{D})$, the order of nickel-mediated homocoupling and cross-linking with acid dichloride is reversed.

Monoporphyrin $\mathbf{4 F b}$ was synthesized by the condensation of aldehydes 1 and 2 and dipyrromethane 3 , followed by oxidation with $p$-chloranil. After treatment with $\mathrm{Zn}(\mathrm{OAc})_{2}, 4 \mathrm{Zn}$ was isolated in $25 \%$ yield in two steps. The homocoupling reaction of $\mathbf{4 Z n}$ was performed to result in the bisporphyrin $\mathbf{5 Z n _ { 2 }}$. Because the solubility of $\mathbf{5} \mathbf{Z} \mathbf{n}_{\mathbf{2}}$ was very low in various solvents, the purification of $\mathbf{5} \mathbf{Z n}_{\mathbf{2}}$ was difficult at this stage.

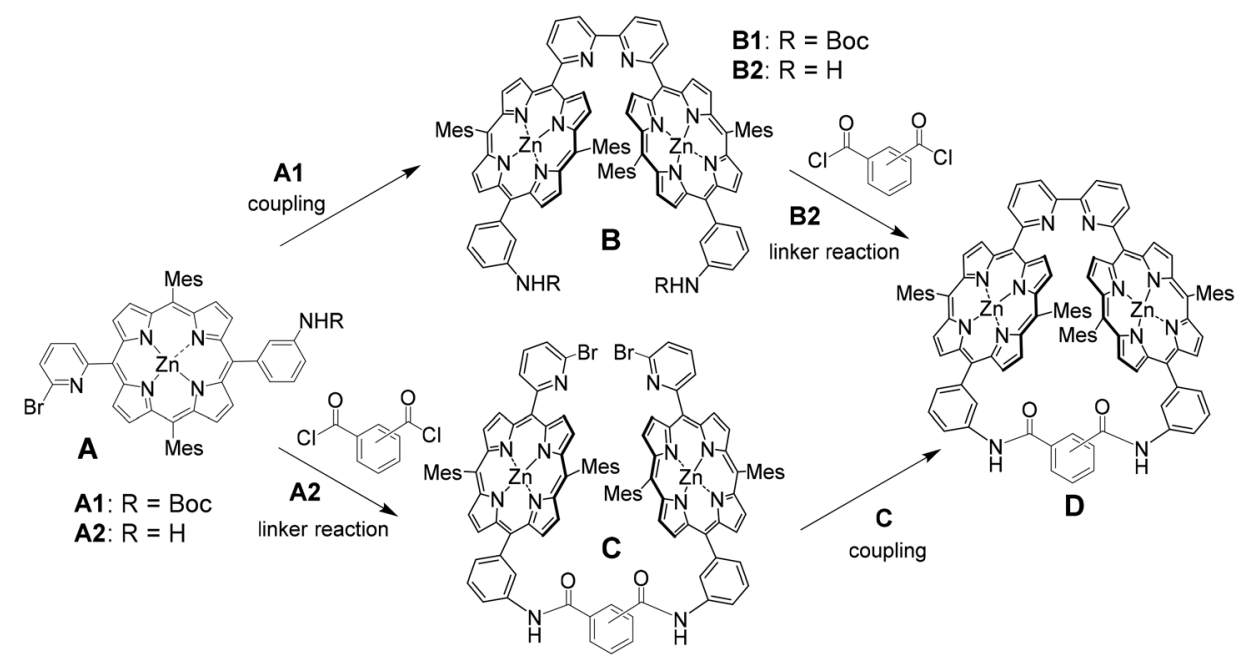

Scheme 1 Two synthetic plans to construct cofacial cyclic bisporphyrins $\left(Z_{2}-C P 2_{o, m, p}\right)$. 


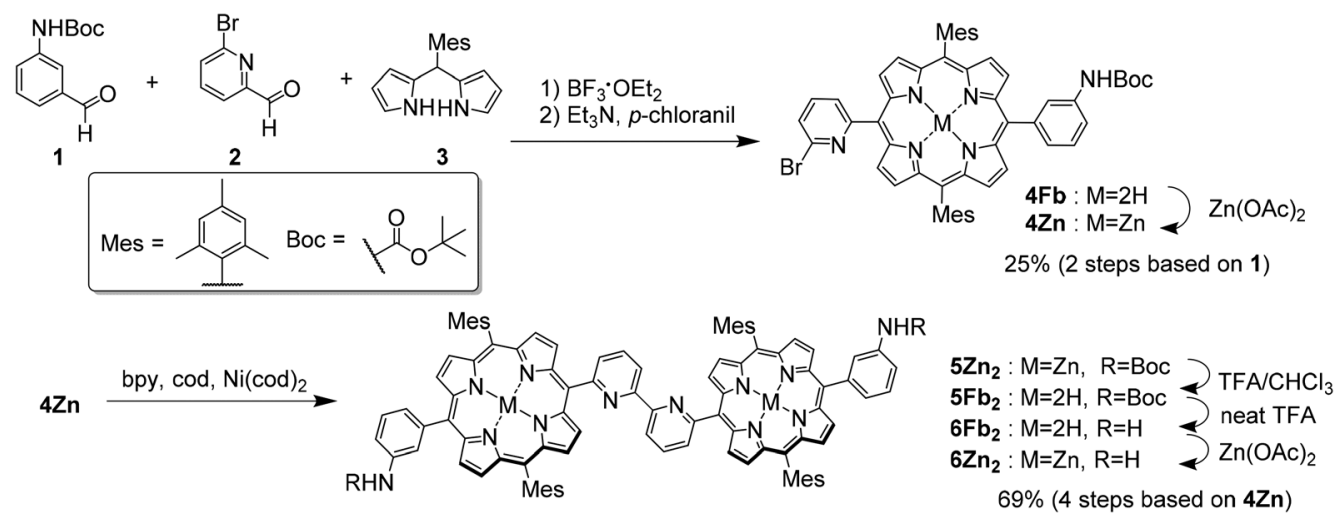

Scheme 2 Synthesis of acyclic bisporphyrin $6 \mathrm{Zn}_{2} ;$ bpy $=2,2^{\prime}$-bipyridine and cod $=1,5$-cyclooctadiene.

Therefore, the zinc ions were removed in the presence of trifluoroacetic acid (TFA) to afford free-base bisporphyrin $\mathbf{5} \mathbf{F b}_{\mathbf{2}}$, $\mathbf{5} \mathbf{F b}_{2}$ was isolated by preparative gel permeation chromatography (GPC). The Boc-protecting groups in $\mathbf{5} \mathbf{F b}_{\mathbf{2}}$ were subsequently removed with neat TFA to afford $\mathbf{6} \mathbf{F b}_{2}$. Finally, zinc ions were re-introduced into the two porphyrin moieties of $\mathbf{6} \mathbf{F b}_{\mathbf{2}}$ to afford $\mathbf{6} \mathbf{Z n}_{\mathbf{2}}$ in $69 \%$ yield in four steps (Scheme 2).

Macrocyclization of $\mathbf{6} \mathbf{Z n}_{2}$ with isophthaloyl dichloride was examined under various conditions to produce the diamide $\mathbf{Z n}_{\mathbf{2}}-\mathbf{C P} \mathbf{2}_{\boldsymbol{m}}$. To a diluted diamine solution of $\mathbf{6 Z n _ { 2 }}$ in dichloromethane (0.5 or $0.2 \mathrm{mM}), 1.5$ equivalents of isophtaloyl dichloride solution $(0.9 \mathrm{mM})$ were slowly added with a syringe pump for $12 \mathrm{~h}$ in the presence of pyridine (4 equiv.) as a base. The reaction mixtures were analyzed by analytical high-performance liquid chromatography (HPLC) with a CN-MS column using a pyridine-based eluent, followed by matrixassisted laser desorption ionization-time of flight (MALDI-TOF) mass spectrometry. An HPLC chart and a MALDI-TOF mass spectrum are shown in Fig. 2 and Fig. S9 and S10, respectively, in the ESI. $\dagger$

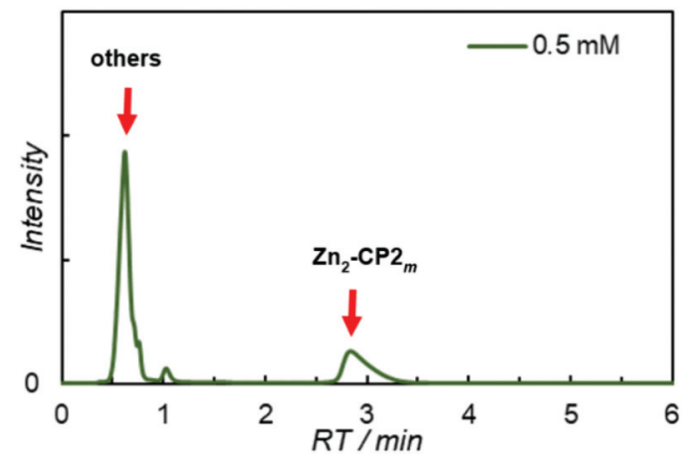

Fig. 2 HPLC chart of a crude mixture after reaction of $6 \mathrm{Zn}_{2}(0.5 \mathrm{mM})$ with isophthaloyl dichloride. Column: Cosmosil 5CN-MS (7.5 mm I.D. $\times$

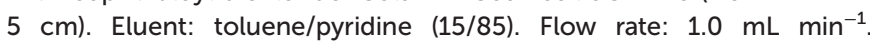
Monitored at $563 \mathrm{~nm}$. Cyclic diamide $\mathrm{Zn}_{2}-\mathrm{CP2} 2_{m}$ was eluted at a RT of 2.9 min (HPLC yield: 15\%). The most other components were eluted up to a RT of 1.5 min without retention.
In the HPLC chart, only the target macrocyclic compound $\mathbf{Z n}_{2}-\mathbf{C P} \mathbf{2}_{\boldsymbol{m}}$ was retained on the column (retention time (RT) $2.9 \mathrm{~min}$ ), and the linear compounds and the larger macrocyclic compound $\mathbf{Z n}_{4}-\mathbf{C P 4} \mathbf{m}_{m}$ were eluted in the initial RT region up to $1.5 \mathrm{~min}$. In the MALDI-TOF mass spectrum, the relative intensities did not reflect their yields. In general, cyclic compounds such as $\mathbf{Z n}_{2}-\mathbf{C P} 2_{m}$ and $\mathbf{Z n _ { 4 }}-\mathbf{C P} \mathbf{4}_{m}$ have a significant appearance as compared to linear porphyrin derivatives.

Therefore, the mass spectral data were used only for the characterization of the fractions by HPLC analysis. The HPLCbased yields of $\mathbf{Z n}_{2}-\mathbf{C P} 2_{m}$ were estimated to be 15 and $28 \%$, respectively, for 0.5 and $0.2 \mathrm{mM}$ solutions without metal-template conditions. Although the dilution condition of $0.2 \mathrm{mM}$ was better than that of $0.5 \mathrm{mM}$, further dilution of the system was not realistically applicable to scale up the system. Therefore, metal-templated synthesis was tested at a concentration of $0.2 \mathrm{mM}$ in the presence of one equivalent of zinc, silver, and copper ions to improve the yield of the target

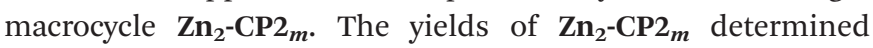
from HPLC (Fig. S11 in the ESI $\dagger$ ) are presented in Table 1. Addition of 1 equiv. of cationic $\mathrm{Zn}(\mathrm{OTf})_{2}$ and $\mathrm{Ag}(\mathrm{OTf})$ improved the yield to approximately 50\%. When 1 equiv. of zinc chloride, zinc acetate, and excess amounts of $\mathrm{Zn}(\mathrm{OTf})_{2}$ were used, the yields decreased compared with those in the absence of metal ions. $\mathrm{Cu}(\mathrm{OTf})_{2}$ was ineffective in yielding $\mathrm{Zn}_{2}-\mathbf{C P} 2_{m}$. In the cases of $\mathrm{Cu}(\mathrm{OTf})_{2}$ and 5 equiv. of $\mathrm{Zn}(\mathrm{OTf})_{2}$,

Table 1 Yields of $\mathrm{Zn}_{2}-\mathrm{CP} \mathbf{2}_{m}$ in the cyclization reaction

\begin{tabular}{llll}
\hline Entry & Metal (1 eq.) & $\mathbf{6 Z n}_{\mathbf{2}}$ conc. (mM) & $\mathbf{Z n}_{\mathbf{2}}$-CP2 ${ }_{\boldsymbol{m}}$ HPLC Yield (\%) \\
\hline 1 & - & 0.5 & 15 \\
2 & - & 0.2 & 28 \\
3 & $\mathrm{Zn}(\mathrm{OTf})_{2}$ & 0.2 & 48 \\
4 & $\mathrm{Ag}(\mathrm{OTf})$ & 0.2 & 50 \\
5 & $\mathrm{Zn}(\mathrm{OAc})_{2}$ & 0.2 & 0 \\
6 & $\mathrm{ZnCl}{ }_{2}$ & 0.2 & 3 \\
7 & $\mathrm{CuI}$ & 0.2 & 4 \\
8 & $\mathrm{Cu}(\mathrm{OTf})_{2}{ }^{a}$ & 0.2 & 6 \\
9 & $\mathrm{Zn}(\mathrm{OTf})_{2}{ }^{a}$ & 0.2 & 8
\end{tabular}

${ }^{a} \mathrm{Zn}(\mathrm{OTf})_{2} 5$ eq. 
(a)

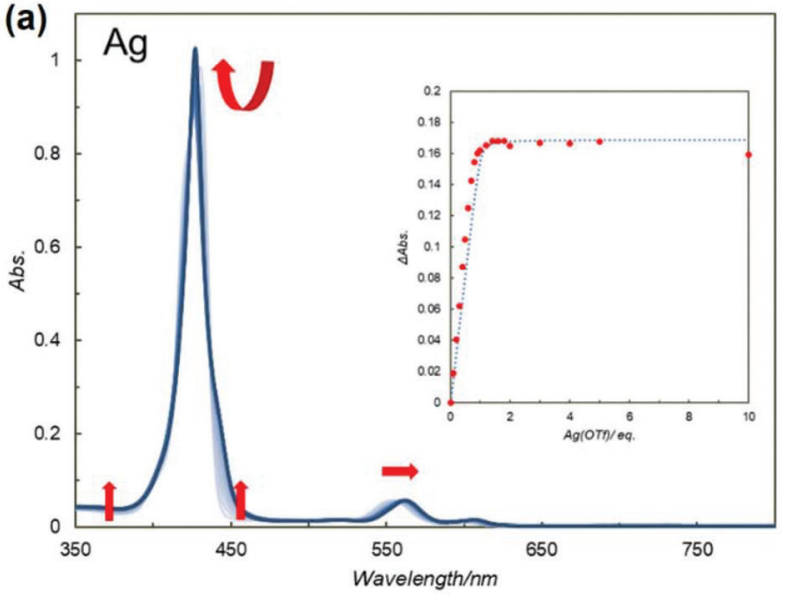

(b)

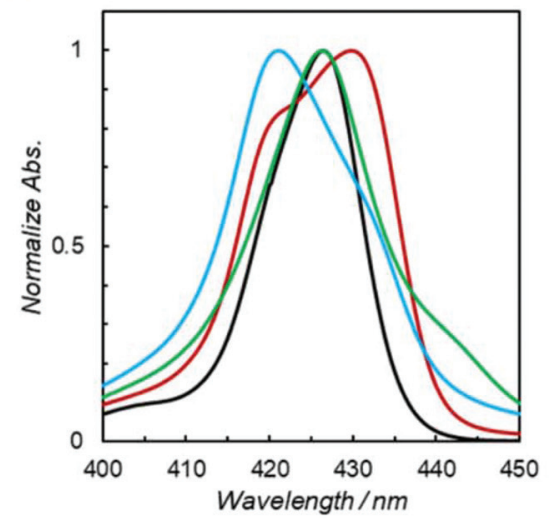

Fig. 3 (a) UV-vis spectral change of $5 \mathrm{Zn}_{2}\left(7.5 \times 10^{-6} \mathrm{M}\right)$ during titration with $\mathrm{Ag}(\mathrm{OTf})$ in $\mathrm{CHCl}_{3}$. (Inset) The relationship between the change of absorption at $450 \mathrm{~nm}$ and equivalents of added Ag(OTf). A curve fitting analysis is shown as a dotted line. (b) Normalized overlaid UV-vis spectra (in $\mathrm{CHCl}_{3}$ ) of $\mathbf{4 Z n}$ (black), $5 \mathrm{Zn}_{2}$ (red), $5 \mathrm{Zn}_{2}$ with 1 equiv. of $\mathrm{Zn}(\mathrm{OTf})_{2}$ (cyan), $5 \mathrm{Zn}_{2}$ with 1 equiv. of Ag(OTf) (green) between 400 and $450 \mathrm{~nm}$. The whole spectra $(350-650 \mathrm{~nm})$ are presented in Fig. S14† as (A)-(D).

some precipitates (probably insoluble complexes composed of metal ions and porphyrin derivatives) were produced, which were separated before the HPLC analysis. One of the reasons for the low yields was the formation of precipitates.

To obtain insight into the effects of metal ions on macrocyclization, UV-vis titration experiments for $\mathbf{5 Z n}_{2}\left(7.5 \times 10^{-6} \mathrm{M}\right)$ with $\mathrm{Ag}(\mathrm{OTf}), \mathrm{Zn}(\mathrm{OTf})_{2}$, and $\mathrm{Cu}(\mathrm{OTf})_{2}$ were conducted in $\mathrm{CHCl}_{3}$ (Fig. 3a, and Fig. S12 and S13†). In the case of $\mathrm{Ag}$ (OTf) and $\mathrm{Zn}(\mathrm{OTf})_{2}$, complexation of $\mathbf{5} \mathbf{Z n} \mathbf{n}_{\mathbf{2}}$ with metal ions converged to $1: 1$ even in the presence of 1 equiv. of metal ions under diluted conditions (the insets of Fig. 3a and S12 $\dagger$ ), whereas further complexation or transformation occurred after the formation of a $1: 1$ complex in the presence of $\mathrm{Cu}(\mathrm{OTf})_{2}$ (inset of Fig. S13 ). These results suggest that one equivalent of $\mathrm{Ag}$ (OTf) and $\mathrm{Zn}(\mathrm{OTf})_{2}$ is sufficient and appropriate to form 1:1 complexes.

The UV-vis spectra of $\mathbf{4 Z n}$ and $\mathbf{5} \mathbf{Z n}_{\mathbf{2}}$ in the absence and presence of 1 equiv. of $\mathrm{Zn}(\mathrm{OTf})_{2}$ or $\mathrm{Ag}$ (OTf) recorded in $\mathrm{CHCl}_{3}$ are shown in Fig. S14. $\dagger$ The spectral shapes and peak maxima of the Soret bands varied slightly. To compare the Soret bands, the overlaid spectra are shown in Fig. 3b. In bis(porphyrin) systems, the exciton coupling model ${ }^{10,30,31}$ is useful for qualitatively discussing the relative orientation between the two porphyrins. As compared to the UV-vis spectrum of zinc porphyrin monomer $4 \mathbf{Z n}(427 \mathrm{~nm})$, in which there is no exciton coupling, metal-free bipyridine $\mathbf{5} \mathbf{Z n}_{\mathbf{2}}$ gave split Soret bands at 420 and $430 \mathrm{~nm}$, whose peaks were both blue and red-shifted. On the one hand, the red-shifted band is ascribed to the headto-tail type of excitonic coupling between the two transition dipoles of $\mathrm{X}$ in the anti-conformation of $\mathbf{5} \mathbf{Z n}_{\mathbf{2}}$, as shown in Fig. 4. On the other hand, the blue-shifted band is because of excitonic couplings of the parallel orientation between the two transition dipoles of $\mathrm{Y}$ and the oblique orientation of $\mathrm{X}$ in the syn conformation (Fig. 4). Therefore, the metal-free bipyridine $\mathbf{5 Z n _ { 2 }}$ adopts both anti- and syn-conformations by freely rotating along the $\mathrm{C}-\mathrm{C}$ bond in the bipyridyl moiety. In the presence of 1 equiv. of $\mathrm{Zn}(\mathrm{OTf})_{2}$, the red-shifted Soret band significantly decreased, whereas the blue-shifted band increased. These results indicate that the syn conformation was predominantly formed by the coordination of zinc ions on the bipyridyl
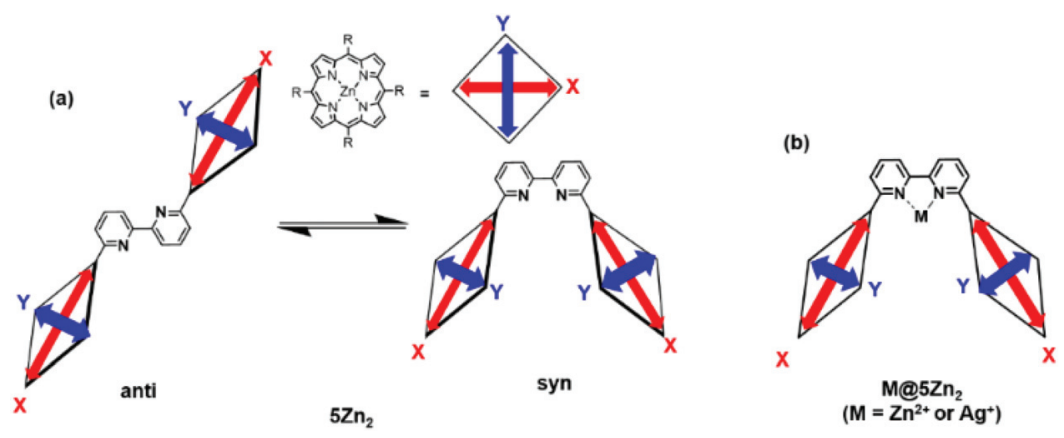

Fig. 4 Interaction of transition dipole moments of the bisporphyrin. 
part to fix the rotation along the $\mathrm{C}-\mathrm{C}$ bond. In the case of $\mathrm{Ag}$ (OTf), since the red-shifted band decreased, the decrease in the anti-conformation was confirmed by the coordination of silver ions on the bipyridyl. However, the blue-shifted Soret band was not remarkable. This result probably because of the differences in ion radii of $\mathrm{Zn}(\mathrm{II})(0.60 \AA)$ and $\mathrm{Ag}(\mathrm{I})(0.67 \AA)$. Exciton coupling is highly sensitive to the relative distance between the transition dipoles. Both 1 equiv. of $\mathrm{Zn}(\mathrm{OTf})_{2}$ and $\mathrm{Ag}(\mathrm{OTf})$ acted as preferable metal templates to fix the syn conformation of $\mathbf{5 Z n}_{\mathbf{2}}$. Notably, real macrocyclization was performed in $\mathbf{6} \mathbf{Z n}_{2}$, in which two amino groups exist on the terminal parts. Therefore, selective interactions between $\mathrm{Zn}(\mathrm{OTf})_{2}$ (or Ag(OTf)) and the 2,2'-bipyridyl moiety in $\mathbf{6} \mathbf{Z n _ { 2 }}$ are required, because the cationic metal ions may also interact with the terminal amino groups. If more than 1 equiv. of the metal template is added, the undesired interactions with the amino groups result in precipitates, and the reactivity of the amines interacting with acyl chlorides may decrease. Therefore, excess amounts of $\mathrm{Zn}(\mathrm{OTf})_{2}$ and $\mathrm{Ag}(\mathrm{OTf})$ should not be added to the metal-templated macrocyclization system.

Another route $\left(\mathbf{A} \rightarrow \mathbf{C} \rightarrow \mathbf{D}\right.$ in Scheme 1) to obtain $\mathbf{Z n _ { 2 }}-\mathbf{C P} 2_{m}$ was also examined, as shown in Scheme 3. Removal of Boc groups on $4 \mathrm{Zn}$ was performed by treatment with TFA to obtain 7Fb. Condensation of $\mathbf{7 F b}$ ( 2 equiv.) with isophthaloyl dichloride in dichloromethane gave bisamide $\mathbf{8} \mathbf{F b}_{\mathbf{2}}$, which was reacted with zinc acetate to afford $\mathbf{8 Z n}_{\mathbf{2}}$ in $38 \%$ yield in three steps. As a key step, nickel-mediated macrocyclization was applied to $\mathbf{8} \mathbf{Z n}_{\mathbf{2}}$ under several conditions. However, the target macrocyclic compound, $\mathbf{Z n}_{2}-\mathbf{C P} \mathbf{2}_{m}$, was obtained in a low yield (3\% from HPLC in Fig. S15 $\dagger$ ). Therefore, the first synthetic route, $\mathbf{A} \rightarrow \mathbf{B} \rightarrow \mathbf{D}$, shown in Scheme 1, was developed.

To obtain $\mathbf{Z n} \mathbf{n}_{\mathbf{2}}-\mathbf{C P} \mathbf{2}_{m}$, metal-templated synthesis of $\mathbf{6} \mathbf{Z n}_{\mathbf{2}}$ with isophthaloyl dichloride in the presence of 1 equiv. of $\mathrm{Zn}$ (OTf $)_{2}$ or $\mathrm{Ag}(\mathrm{OTf})$ was the most appropriate. Therefore, the same conditions were applied to obtain $\mathbf{Z n}_{\mathbf{2}}-\mathbf{C P} \mathbf{2}_{\boldsymbol{p}}$ and $\mathbf{Z n}_{\mathbf{2}^{-}}$ CP2 o using terephthaloyl and phthaloyl dichlorides, instead of isophthaloyl dichloride. The yields of $\mathbf{Z n}_{2}-\mathbf{C P} \mathbf{2}_{p}$ and $\mathbf{Z n}_{2}-\mathbf{C P 2} \mathbf{2}_{\boldsymbol{o}}$ were determined by HPLC using a CN-MS column. The chromatograms of the crude reaction mixtures are shown in Fig. 5, and the reaction yields are summarized in Table 2. On the CN-MS column using pyridine as the eluent, only the target cyclic compounds were significantly retained. The RTs were 9.2 and $15.6 \mathrm{~min}$ for $\mathbf{Z} \mathbf{n}_{\mathbf{2}}-\mathbf{C P} \mathbf{2}_{\boldsymbol{p}}$ and $\mathbf{Z n _ { 2 }}-\mathbf{C P} \mathbf{2}_{\boldsymbol{o}}$, respectively, with a flow rate of $0.5 \mathrm{~mL} \mathrm{~min}^{-1}$. The RTs of $\mathbf{Z n}_{2}-\mathbf{C P 2} \mathbf{p}_{\boldsymbol{p}}$ and $\mathbf{Z n}_{\mathbf{2}^{-}}$
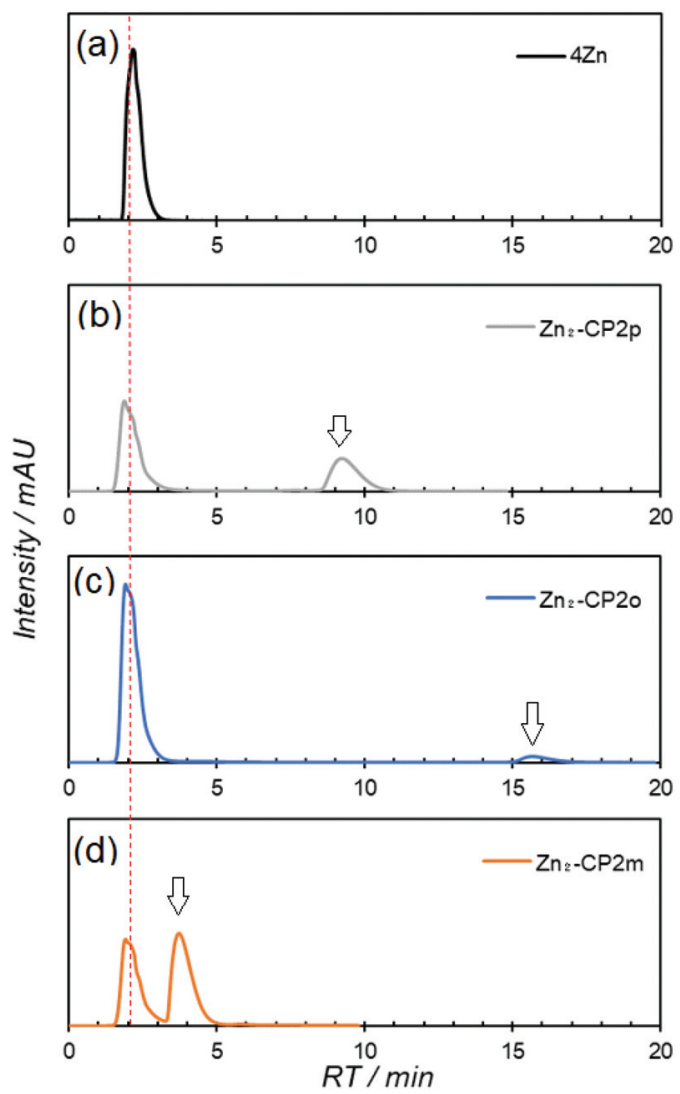

Fig. 5 HPLC charts of (a) $4 Z n_{2}$, crude mixtures after the reaction of $6 \mathrm{Zn}_{2}(0.5 \mathrm{mM})$ in the presence of 1 equiv. of $\mathrm{Zn}(\mathrm{OTf})_{2}$ with (b) terephthaloyl dichloride, (c) phthaloyl dichloride, and (d) isophthaloyl dichloride. Column: Cosmosil 5CN-MS (7.5 mm I.D. $\times 5 \mathrm{~cm}$ ), eluent: pyridine $100 \%$, flow late: $0.5 \mathrm{~mL} \mathrm{~min}^{-1}$, monitored at $563 \mathrm{~nm}$. Arrows indicate the peaks corresponding to (b) $\mathrm{Zn}_{2}-\mathrm{CP} 2_{p}$, (c) $\mathrm{Zn}_{2}-\mathrm{CP} 2_{o}$, and (d) $\mathrm{Zn}_{2}-\mathrm{CP} 2_{m}$, respectively.

$\mathbf{C P} 2_{o}$ were significantly longer than those of $\mathbf{Z n}_{\mathbf{2}}-\mathbf{C P} \mathbf{2}_{\boldsymbol{m}}$ (4.0 $\mathrm{min}$ ) recorded under the same conditions (Fig. $5 \mathrm{~d}$ ). It is noted that all other compounds, except for the cyclic dimers, were eluted at RT 2 min without retention.

In both cases using terephthaloyl and phthaloyl dichlorides, no macrocyclic compounds were obtained in the absence of $\mathrm{Zn}(\mathrm{OTf})_{2}$ or $\mathrm{Ag}(\mathrm{OTf})$, whereas macrocyclic compounds, $\mathbf{Z n}_{\mathbf{2}^{-}}$ $\mathbf{C P} 2_{p}$ and $\mathbf{Z n}_{2}-\mathbf{C P} 2_{o}$, were observed in the mixtures prepared

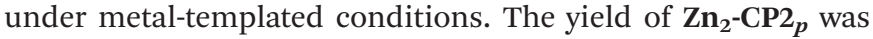

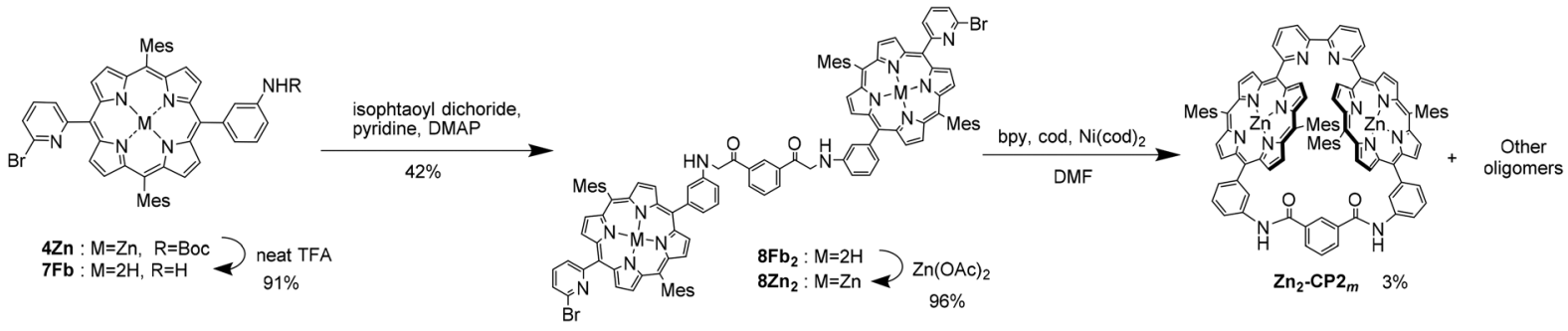

Scheme 3 Alternative synthetic route to cyclic bisporphyrin $\mathrm{Zn}_{2}-\mathrm{CP} 2_{m}$. 
Table 2 Yields of $\mathrm{Zn}_{2}-\mathrm{CP} \mathbf{2}_{p}$ and $\mathrm{Zn}_{2}-\mathrm{CP} \mathbf{2}_{\mathrm{o}}$ in the cyclization reaction

\begin{tabular}{llll}
\hline & & & Metal \\
Entry & Linker (1.5 eq.) & $\begin{array}{l}\mathbf{Z n}_{2}-\mathbf{C P 2} \mathbf{2}_{\boldsymbol{p}} \text { or } \\
\mathbf{Z n}_{2} \text {-CP2 } \\
\text { HPLC yield (\%) }\end{array}$ \\
\hline 1 & Terephthaloyl dichloride $(p)$ & - & 0 \\
2 & Terephthaloyl dichloride $(p)$ & $\mathrm{Zn}(\text { OTf })_{2}$ & 19 \\
3 & Terephthaloyl dichloride $(p)$ & Ag(OTf) & 24 \\
4 & Phthaloyl dichloride $(o)$ & - & 0 \\
5 & Phthaloyl dichloride $(o)$ & Zn(OTf $)_{2}$ & 5 \\
6 & Phthaloyl dichloride $(o)$ & Ag(OTf) & 3
\end{tabular}

approximately $20 \%$, whereas that of $\mathbf{Z n}_{2}-\mathbf{C P 2} \mathbf{2}_{o}$ was less by several percent. The reason for the low yields of $\mathbf{Z n}_{2}-\mathbf{C P} \mathbf{2}_{\boldsymbol{o}}$ is that phthalimide derivatives, such as $\mathbf{9}$ in Fig. S16, $\dagger$ were formed significantly, which were detected by MALDI-TOF mass spectrometry (Fig. S17†). While the yield of $\mathbf{Z} \mathbf{n}_{2}-\mathbf{C P} 2_{o}$ was very low, it was never obtained in the absence of a metal template. Therefore, the metal-template method is especially effective for the preparation of the kinetically disadvantageous phthaldiamide $\mathbf{Z n} \mathbf{n}_{\mathbf{2}}-\mathbf{C P} \mathbf{2}_{\boldsymbol{o}}$, compared with phthalimide derivatives, such as 9, which are immediately formed from an amine part and phthaloyl dichloride. The yield of $\mathbf{Z n}_{\mathbf{2}}-\mathbf{C P} \mathbf{2}_{\boldsymbol{p}}$ was slightly increased using $\mathrm{Ag}(\mathrm{OTf})$ instead of $\mathrm{Zn}(\mathrm{OTf})_{2}$, suggesting that the larger $\operatorname{Ag}(\mathrm{I})$ ion is beneficial for obtaining bis(porphyrin) $\mathbf{Z n}_{\mathbf{2}}-\mathbf{C P} \mathbf{2}_{\boldsymbol{p}}$, in which the two amide parts are located more apart than those in $\mathbf{Z n}_{\mathbf{2}}-\mathbf{C P} \mathbf{2}_{\boldsymbol{m}}$.

\section{Efficient isolation}

After the metal-templated macrocyclization, $\mathbf{Z n}_{2}-\mathbf{C P} \mathbf{2}_{m}, \mathbf{Z n}_{\mathbf{2}^{-}}$ $\mathbf{C P} \mathbf{2}_{\boldsymbol{o}}$, and $\mathbf{Z n}_{\mathbf{2}}-\mathbf{C P} \mathbf{2}_{\boldsymbol{p}}$ were obtained as mixtures, including

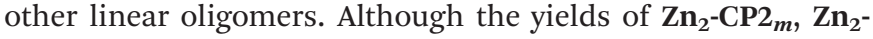
$\mathbf{C P} 2_{o}$ and $\mathbf{Z n}_{2}-\mathbf{C P} 2_{p}$ were moderate or significantly low compared with other byproducts, isolation of the cyclic compounds was accomplished efficiently using a preparative CN-MS column using pyridine as an eluent. Under these conditions, all the compounds, except for the cyclic compounds, were eluted first without any retention, and then, almost only the cyclic compounds were eluted independently. As a result,

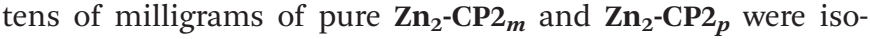
lated, and a few milligrams of $\mathbf{Z n}_{2}-\mathbf{C P} \mathbf{2}_{o}$ were obtained. It is noted that HPLC yields determined from the crude mixtures and the corresponding isolated yields were almost the same, indicating that the decrease in the isolated yields during the purification process was suppressed.

\section{Structural analyses of macrocycles on ${ }^{1} \mathrm{H}$ NMR}

To estimate the conformational structures of the macrocyclic

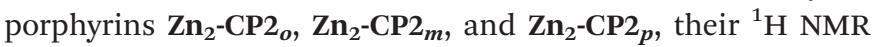
spectra in pyridine- $d_{5}$ are compared in Fig. 6 . In pyridine- $d_{5}$, two pyridine molecules coordinate to the two zinc parts to form five-coordinated complexes. Because the exchange rate of the coordinating pyridine molecules to peripheral non-coordinating pyridine is high at room temperature $\left(\mathrm{ca} .23-25^{\circ} \mathrm{C}\right)$, it is difficult to detect the coordinating pyridine in NMR spectroscopy.

Consequently, the labile coordination behavior of pyridine eliminates the anisotropy of coordination. Therefore, only the conformational changes in the macrocyclic frames can be considered in the NMR spectra. The ${ }^{1} \mathrm{H}$ NMR spectra of $\mathbf{Z n}_{\mathbf{2}}-\mathbf{C P 2} \mathbf{2}_{\boldsymbol{o}}$ (Fig. 6a) and $\mathbf{Z n}_{2}-\mathbf{C P 2} 2_{m}$ (Fig. 6b) show a pseudo $C_{2 \mathrm{v}}$ symmetric

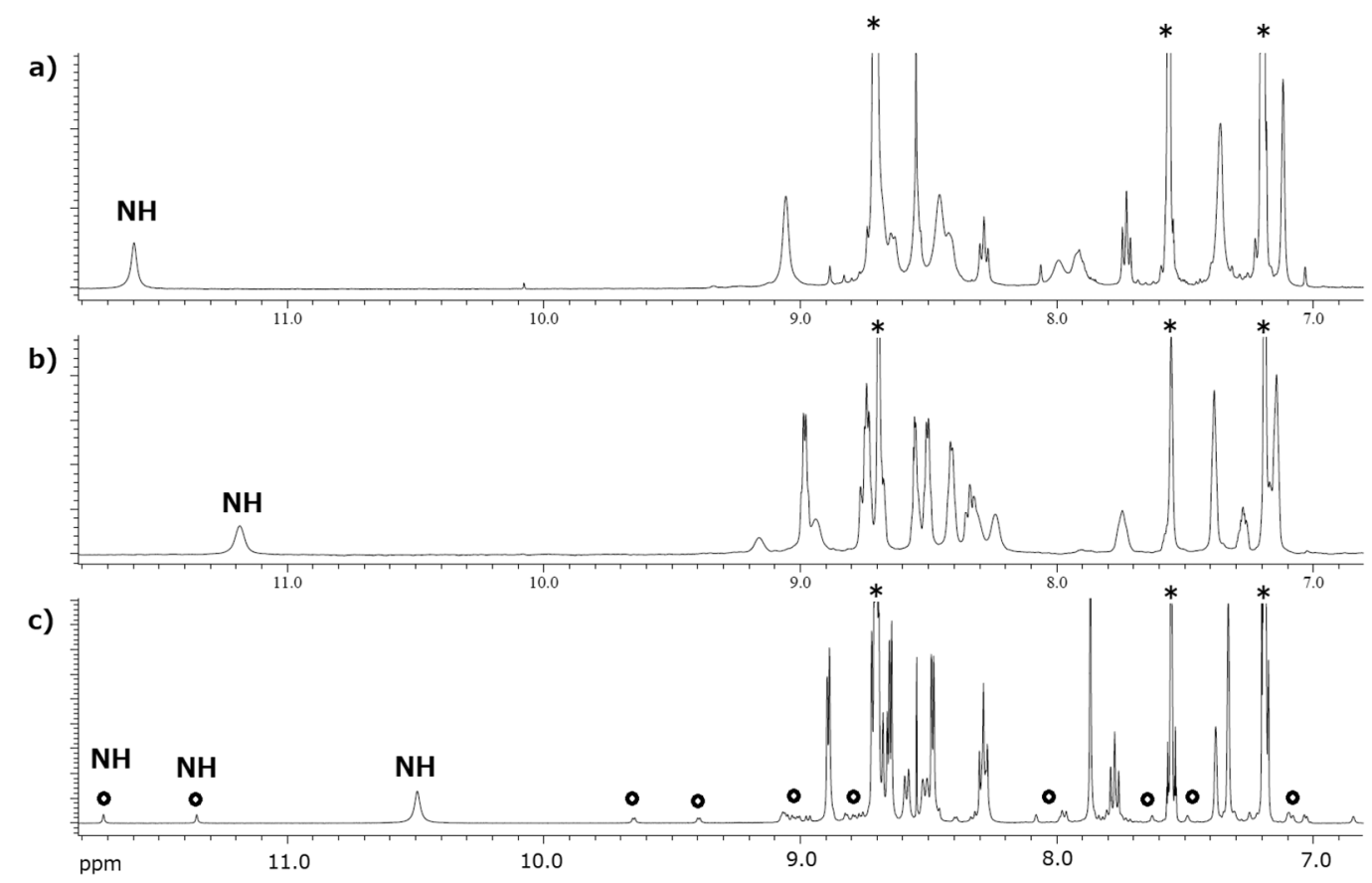

Fig. $6{ }^{1} \mathrm{H}$ NMR (500 MHz) spectra of (a) $\mathrm{Zn}_{2}-\mathrm{CP} 2_{o}$, (b) $\mathrm{Zn}_{2}-\mathrm{CP} 2_{m}$, and (c) $\mathrm{Zn}_{2}-\mathrm{CP} 2_{p}$ in pyridine- $\mathrm{d}_{5}$ (12-7 ppm). Asterisks indicate the signals of pyridines. Open circles in (c) indicate the signals of the minor isomer. 
structure at room temperature, respectively, indicating that the two porphyrin planes are cofacial on average. In contrast, two conformational isomers were observed for $\mathbf{Z n}_{2}-\mathbf{C P} \mathbf{2}_{\boldsymbol{p}}$ (Fig. 6c). The major isomer is a pseudo $C_{2 \mathrm{v}}$ symmetric structure, whereas the minor isomer (indicated by open circles in Fig. 6c) is not symmetric. The chemical shifts of amide- $\mathrm{NH}$ groups in $\mathbf{Z n}_{2}-\mathbf{C P} 2_{o}, \mathbf{Z n}_{2}-\mathbf{C P} 2_{m}$, and $\mathbf{Z n}_{2}-\mathbf{C P} 2_{p}$ (for the major isomer) are observed at 11.58, 11.17, and 10.48 ppm, respectively. These differences occur when the two cofacial porphyrins are close to each other, and as a result, the amide protons are affected by the ring current produced by the nearby porphyrin moieties. In particular, the amide protons of $\mathbf{Z n}_{2}-\mathbf{C P 2} \mathbf{o}_{\boldsymbol{o}}$ are deshielded by existing just outside the ring currents. In the case of the amide protons in $\mathbf{Z} \mathbf{n}_{2}-\mathbf{C P} \mathbf{2}_{\boldsymbol{m}}$ and $\mathbf{Z} \mathbf{n}_{\mathbf{2}}-\mathbf{C P} \mathbf{2}_{\boldsymbol{p}}$, the degree of deshielding effects was smaller. Therefore, the order of the lower chemical

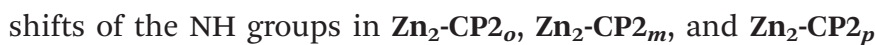
(for the major isomer) suggests that the average distances of the two porphyrins in the cofacial porphyrins increase in the

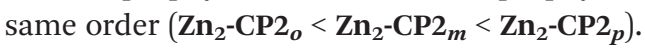

The assignments of all the ${ }^{1} \mathrm{H}$ and ${ }^{13} \mathrm{C}$ NMR (Fig. S19†) signals of $\mathbf{Z n}_{2}-\mathbf{C P} 2_{m}$ were obtained using various two-dimensional NMR techniques, namely $\mathrm{HH}$-correlation spectroscopy (HH-COSY) (15 mM) (Fig. S20 †), heteronuclear single quantum correlation (HSQC) (15 mM) (Fig. S21†), heteronuclear multiple bond coherence (HMBC) (15 mM) (Fig. S22†), and nuclear Overhauser effect spectroscopy (NOESY) (6 mM) (Fig. S23†). The assignments and observed NOE correlations are shown in Fig. S24. $\dagger$ The chemical shifts of aromatic parts, $\operatorname{Ar}-15, \operatorname{Ar}(\mathrm{m})-18,19$, and 20 varied slightly in the different NMR samples (15 and $6 \mathrm{mM}$ ) prepared from the same $\mathbf{Z n}_{\mathbf{2}}-\mathbf{C P} \mathbf{2}_{\boldsymbol{m}}$ material. The chemical shifts are presented in Table S1 in the ESI. $\uparrow$ These results suggest that the proton signals of the aromatic parts are significantly affected by the circumstances and concentrations.

Because stronger NOE correlation signals were observed between $\mathrm{NH}-17$ and Ar-16, and $\mathrm{NH}-17$ and $\operatorname{Ar}(\mathrm{m})-20$, the major conformer was determined as syn-1 in Fig. 7, in which the amide groups exist on the near side of $\operatorname{Ar}-16$ and $\operatorname{Ar}(\mathrm{m})-20$. Meanwhile, relatively weaker correlation signals were also observed between $\mathrm{NH}-17$ and Ar-15 and between $\mathrm{NH}-17$ and $\mathrm{Ar}$ (m)-18. These NOE correlations indicate the existence of $\boldsymbol{s y n - 2}$ and anti isomers as minor components. Distinct conformers could not be observed at room temperature. Rapid interconver-
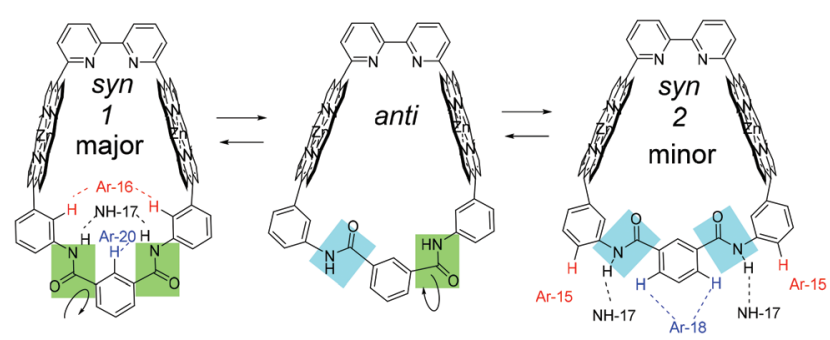

Fig. 7 Exchange among conformers, syn1 (major), anti, and syn2 of $\mathrm{Zn}_{2}-\mathrm{CP} 2_{m}$ sion (conformational changes) between syn-1, anti, and syn-2 was observed at room temperature.

In the case of $\mathbf{Z n}_{2}-\mathbf{C P 2}$, two conformational isomers were clearly separated in the ${ }^{1} \mathrm{H}$ NMR spectra of pyridine- $d_{5}$ at a ratio of $85: 15$ (Fig. 6c and Fig. S25 and S26†). The signal pattern of the major conformer is simple, indicating a symmetric structure, whereas the pattern of the minor isomer is complicated (Fig. S26†). For assignments of the ${ }^{1} \mathrm{H}$ and ${ }^{13} \mathrm{C}$ NMR (Fig. S27†) signals of the major isomer of $\mathbf{Z n}_{2}-\mathbf{C P}{ }_{p}$, various two-dimensional NMR techniques, namely $\mathrm{HH}-\mathrm{COSY}$ (Fig. S28†), HSQC (Fig. S29†), and NOESY (Fig. S30, S31, and $\mathrm{S} 32 \dagger)$, were performed. The assignments and observed NOE correlations in the major conformer are shown in Fig. S33. $\dagger$ As the intense NOE correlation between 10.44 and 7.33 was observed in the major conformer (Fig. S30†), the NH groups in the amide moieties are directed to the porphyrin groups, as illustrated in Fig. 8 (syn).

Parts of correlation signals between the major and minor conformers were observed in the NOESY (Fig. S30, S31, and $\mathrm{S} 32 \dagger)$. The correlations were because of the chemical exchange between the two conformational isomers. The correlated signals among the amide groups, the $\beta$-protons, and the methyl groups on the mesityl moieties are summarized in Table S2.† Other minor signals could not be assigned because of overlapping with the major signals. In the minor conformer, the two NH groups are separately observed at 11.67 and $11.30 \mathrm{ppm}$. The inner methyl group in mesityl moieties in the major conformer at $1.47 \mathrm{ppm}$ was correlated with four methyl groups in the minor conformer at 2.56, 1.98, 0.61, and $-1.04 \mathrm{ppm}$. They are widely distributed. Two of the four methyl groups in the minor conformer are upper-field shifted (0.61 and $-1.04 \mathrm{ppm}$ ), whereas the other two methyl groups in the minor conformer are lower-field shifted (2.56 and $1.98 \mathrm{ppm})$. These results indicate that the two porphyrin moieties are twisted in the minor conformer, and the former two methyl groups are shielded to a significant extent by the oppo-
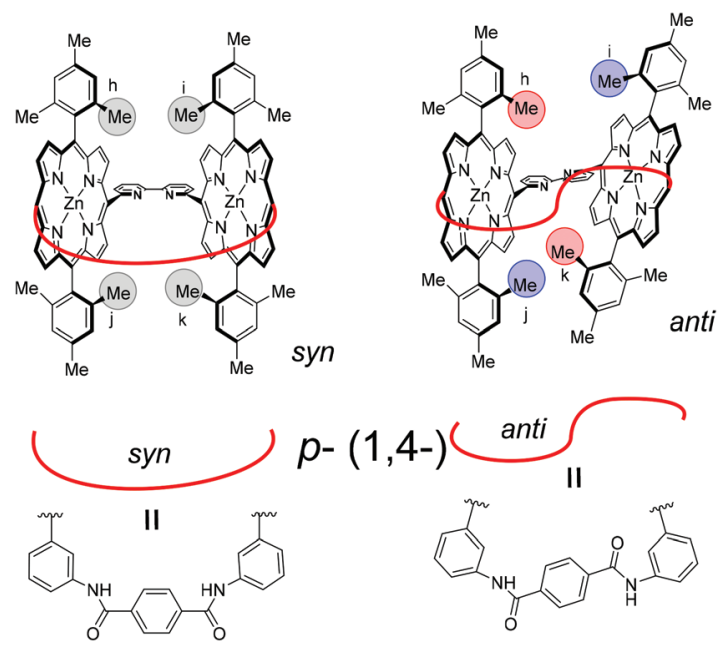

Fig. 8 Schematics of two conformers of $\mathrm{Zn}_{2}-\mathrm{CP} 2_{p}$. (left) Major symmetric syn form and (right) minor unsymmetric anti form. 
site facial porphyrin, whereas the latter two are shielded to a lesser extent. A schematic of the two conformational isomers is shown in Fig. 8 (anti). In the major symmetric form (syn), the $\mathrm{NH}$ groups were directed to the inside of the ring. In the minor non-symmetric form (anti), the two porphyrin groups are twisted, resulting in four methyl groups that are not identical. In the case of $\mathbf{Z n}_{2}-\mathbf{C P} \mathbf{2}_{\boldsymbol{p}}$, the exchange rate between the two

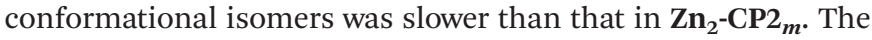
observations are used in the discussion in the last section.

\section{Structural analyses of macrocycles on UV-vis spectra}

In contrast to the NMR spectra, UV-vis spectra reflect the populations of conformational isomers, because the timescale of the measurements is considerably faster than the exchange rate among the conformational isomers. The UV-vis spectra in pyridine are shown in Fig. 9E to compare the Soret bands (410-450 nm) for monomer 4Zn, and $\mathbf{Z n}_{2}-\mathbf{C P} \mathbf{2}_{\boldsymbol{o}, \boldsymbol{m}, \boldsymbol{p}}$. The highest absorption peak in each spectrum was normalized in the spectra. All three cyclic dimers $\left(\mathbf{Z n}_{2}-\mathbf{C P 2} \mathbf{o}_{\boldsymbol{o}, \boldsymbol{m}, \boldsymbol{p}}\right)$ have blueshifted Soret bands compared with the monomer $\mathbf{4 Z n}$, indicating that the two zinc porphyrins in $\mathbf{Z n}_{2}-\mathbf{C P} \mathbf{2}_{\boldsymbol{o}, \boldsymbol{m}, \boldsymbol{p}}$ face each other, as shown in Fig. 10. The excitonic couplings between the two parallel transition dipole components of $\mathrm{Y}$ and the oblique transition dipole component $\mathrm{X}$ contribute to the blue shift. The degrees of the blue shifts and full width at half
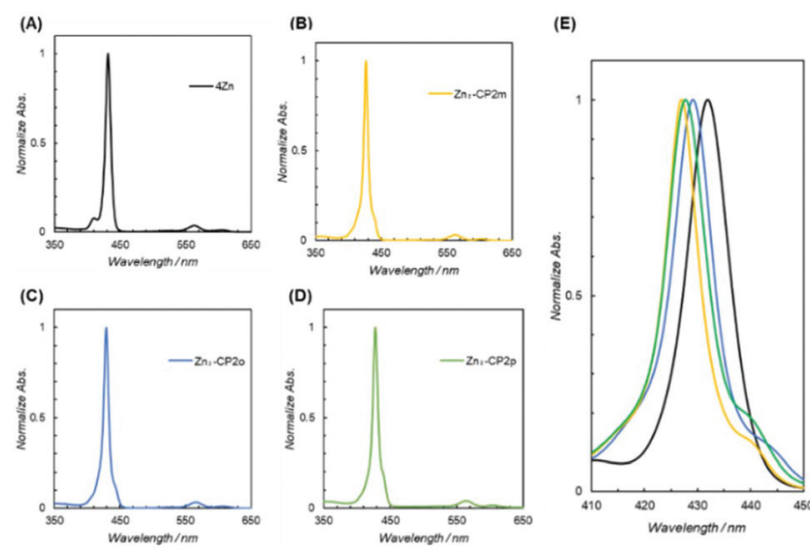

Fig. 9 UV-vis spectra in pyridine of (A) $4 Z n$, (B) $Z n_{2}-C P 2_{m}$, (C) $Z n_{2}-$ $C P 2_{o}$, and (D) $\mathrm{Zn}_{2}-C P 2_{p}$ (E) Overlaid spectra of $(A)-(D)$ in the Soret band region.

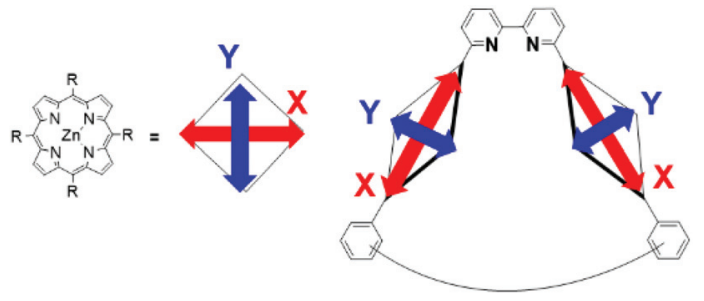

Fig. 10 Interaction of transition dipole moments of the cyclic bisporphyrin. maximum (FWHM) are different among the three compounds, suggesting that the orientation and distance between the two porphyrins in each cyclic dimer are different. In the three blue-shifted spectra, the spectrum of $\mathbf{Z n}_{2}-\mathbf{C P} \mathbf{2}_{m}$ was blueshifted to the highest extent, and the FWHM was narrow. These features indicate that the relative positions of the two porphyrins in $\mathbf{Z n}_{2}-\mathbf{C P} \mathbf{2}_{m}$ are constant and parallel. Although the existence of syn-2 and anti forms of $\mathbf{Z n}_{2}-\mathbf{C P} \mathbf{2}_{m}$ was suggested by the ${ }^{1} \mathrm{H}$ NMR spectrum (Fig. 7), the population of the minor anti isomer was small. In the case of $\mathbf{Z n}_{2}-\mathbf{C P} \mathbf{2}_{p}$, the absorption in the Soret band region was broadened. This is ascribed to the overlapping of the UV-vis spectra of conformers, syn and $\boldsymbol{a n t i}$, on the amide groups (Fig. 8), as observed in the ${ }^{1} \mathrm{H}$ NMR spectrum (Fig. 6). The degree of the blue shift of $\mathbf{Z n}_{2}-\mathbf{C P 2} \mathbf{o}_{\boldsymbol{o}}$ was lowest in the three cyclic porphyrins, although the distance between the two porphyrin groups was expected to be the closest among the three conformers. The UV-vis spectrum of $\mathbf{Z n}_{\mathbf{2}}-\mathbf{C P 2} \mathbf{2}_{\boldsymbol{o}}$ indicates that the two porphyrins adopt a twisted conformation, in which the transition dipoles of $\mathrm{Y}$ adopt an oblique orientation. ${ }^{30}$ In Fig. 11, the possible conformers of $\mathbf{Z} \mathbf{n}_{\mathbf{2}}-\mathbf{C P} \mathbf{2}_{\boldsymbol{o}}$ are presented. The anti-conformers are expected to be twisted. Since the ${ }^{1} \mathrm{H}$ NMR spectrum of $\mathbf{Z n}_{2}$ CP2 $\boldsymbol{o}_{\text {o }}$ showed a relatively simple pattern corresponding to a pseudo-symmetric structure (Fig. 6a), the exchange between the two anti conformers must occur in the NMR timescale.

\section{Calculated models of $\mathrm{Zn}_{2}-\mathrm{CP} 2_{o}, \mathrm{Zn}_{2}-\mathrm{CP} 2_{m}$, and $\mathrm{Zn}_{2}-\mathrm{CP} 2_{p}$}

In Fig. 12, S35, and S36, $\uparrow$ the energy-minimized molecular

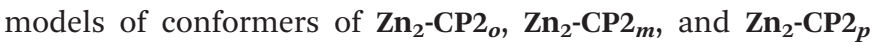
obtained by density-functional theory (DFT) calculations (B3LYP/6-31G(d)) are shown. In the case of $\mathbf{Z n}_{2}-\mathbf{C P 2} \boldsymbol{o}_{\boldsymbol{o}}$, anti form is more stable than the syn form by $4.3 \mathrm{kcal} \mathrm{mol}^{-1}(18.0 \mathrm{~kJ}$ $\mathrm{mol}^{-1}$ ) in a vacuum.
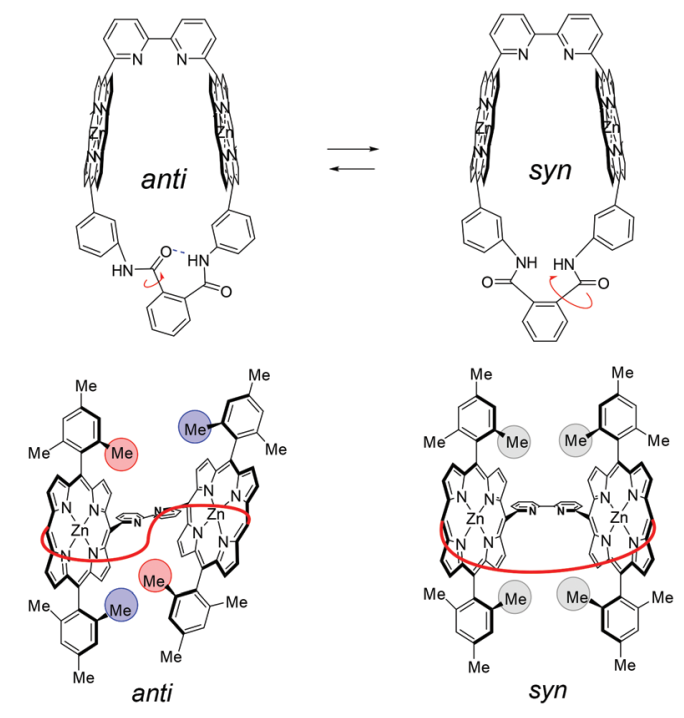

Fig. 11 Schematics of exchange among conformers of $Z_{2}-C P 2_{o}$. (left and right) anti forms and (center) syn form. 


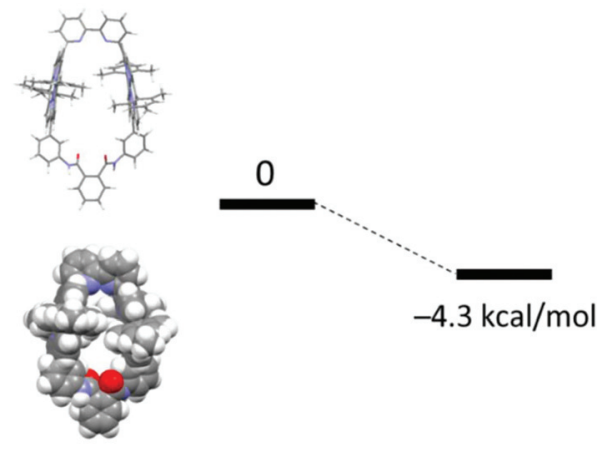

syn

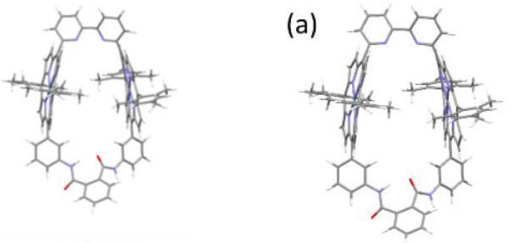

$7.87 \AA$ (b)

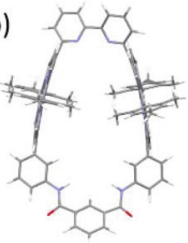

$8.30 \AA$

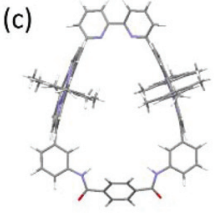

$9.27 \AA$

Fig. 13 Molecular structures and the distances between two zinc ions of (a) anti form of $\mathrm{Zn}_{2}-\mathrm{CP} 2_{o}$, (b) syn-1 form of $\mathrm{Zn}_{2}-\mathrm{CP} 2_{m}$, and (c) syn form of $\mathrm{Zn}_{2}-\mathrm{CP} 2_{p}$ optimized with DFT calculations (B3LYP/6-31G(d) in vacuo). The calculated distances between two zinc ions are presented.

Fig. 12 Molecular structures of syn- and anti-conformers of $\mathbf{Z n}_{2}-C P 2$ 。 optimized with DFT calculations (B3LYP/6-31G(d) in vacuo), and the energy difference.

Intramolecular hydrogen bonding is observed in the anti form, and the two porphyrin moieties are twisted (Fig. 12), as discussed in the previous section.

Two syn forms are compared in $\mathbf{Z n}_{2}-\mathbf{C P} 2_{m}$ (Fig. S35†), and syn-1 is more stable by $6.3 \mathrm{kcal} \mathrm{mol}^{-1}\left(26.4 \mathrm{~kJ} \mathrm{~mol}^{-1}\right)$ in a vacuum. This result is consistent with the NOESY spectrum of $\mathbf{Z n}_{2}-\mathbf{C P} 2_{m}$, in which a stronger correlation signal was observed between Ar-16 and NH-17, and Ar-20 and NH-17 (Fig. S23†).

In the case of $\mathbf{Z n}_{2}-\mathbf{C P} 2_{p}$, syn and anti forms are compared in Fig. S36, $\dagger$ and $\boldsymbol{s y n}$ form is more stable by $5.8 \mathrm{kcal} \mathrm{mol}^{-1}$ $\left(24.3 \mathrm{~kJ} \mathrm{~mol}^{-1}\right)$ in a vacuum. In pyridine- $\mathrm{d}_{5}$ at $298 \mathrm{~K}$, the ratio of syn to anti is $85: 15$, corresponding to $\Delta G^{\circ}=4.3 \mathrm{~kJ} \mathrm{~mol}^{-1}$. The difference in the $\Delta G^{\circ}$ values $\left(\Delta \Delta G^{\circ} 20.0 \mathrm{~kJ} \mathrm{~mol}^{-1}\right)$ corresponds to the solvation energy of pyridine. It is noted that the signals of syn and anti conformers in the ${ }^{1} \mathrm{H}$ NMR spectrum of $\mathbf{Z n}_{\mathbf{2}}-\mathbf{C P} \mathbf{2}_{\boldsymbol{p}}$ are ascribed to the difference in the activation energy between the syn- and anti-conformers of $\mathbf{Z n}_{2}-\mathbf{C P} \mathbf{2}_{\boldsymbol{p}}$ from those of $\mathbf{Z n} \mathbf{n}_{2}-\mathbf{C P} 2_{m}$. The former must be larger than that of $\mathbf{Z n}_{2}-\mathbf{C P} 2_{m}$.

The distances between the two zinc ions in $\mathbf{Z n}_{\mathbf{2}}-\mathbf{C P 2} \mathbf{2}_{\boldsymbol{o}}$ (anti form), $\mathbf{Z n}_{2}-\mathbf{C P} \mathbf{2}_{m}$ (syn form) and $\mathbf{Z n}_{2}-\mathbf{C P} \mathbf{2}_{\boldsymbol{p}}$ (syn form) are estimated to be $7.87,8.30 \mathrm{~A}$, and $9.27 \mathrm{~A}$, respectively. $\$$ The order of the distances between the two porphyrins is consistent with the order of the lower chemical shifts of the $\mathrm{NH}$ groups in $\mathbf{Z n}_{\mathbf{2}^{-}}$ $\mathbf{C P} 2_{o}, \mathbf{Z n}_{2}-\mathbf{C P} 2_{m}$, and $\mathbf{Z n}_{2}-\mathbf{C P 2} 2_{p}$ (for the major isomer) (Fig. 13). The NH protons are located at the edges of the porphyrin moieties. Thus, they are sensitive to the ring current of the nearby porphyrins. In the molecular model of $\mathbf{Z n _ { 2 }}-\mathbf{C P} \mathbf{2}_{\boldsymbol{o}}$, the contribution of the deshielding effect to the $\mathrm{NH}$ groups seems large.

\section{Consideration of retention times on the CN-MS column}

Specific retention phenomena were observed for $\mathbf{Z n}_{\mathbf{2}}-\mathbf{C P} \mathbf{2}_{\boldsymbol{o}}$, $\mathbf{Z n}_{2}-\mathbf{C P} 2_{m}$, and $\mathbf{Z n}_{2}-\mathbf{C P} 2_{p}$ by CN-MS chromatography. Our

\$The B3LYP/6-31G(d) level of theory was used and the contributions from dispersion interactions were not considered for the calculations. Please refer to Fig. S37 in the ESI, $\uparrow$ which presents models constructed using the B3LYP-D3/6$31 \mathrm{G}$ (d) level of theory (in vacuo). Contributions from dispersion interactions were considered for the calculations

group previously observed the specific retention of cyclic zinc porphyrin trimers ${ }^{32}$ and cyclic nickel porphyrin dimers. ${ }^{14}$ Therefore, this report is the third example of a specific retention phenomenon. For specific retention, the structural requirements become obvious. Thus, the compounds are cyclic and have two porphyrin moieties connected via bipyridine. However, these two structural requirements are not sufficient conditions. At present, the mechanism of specific retention remains unclear. To discuss this mechanism, we believe that the collection of more examples of relationships between structures and retention behaviors is necessary. In this report, we have prepared three new cyclic bisporphyrins, $\mathbf{Z n}_{2}-\mathbf{C P 2} \mathbf{o}_{\boldsymbol{o}}, \mathbf{Z n}_{2}-\mathbf{C P 2} \mathbf{2}_{\boldsymbol{m}}$, and $\mathbf{Z n _ { 2 } - \mathbf { C P 2 }}$. Retention behavior is now discussed.

As shown in Fig. 5, the retention times were extended in the

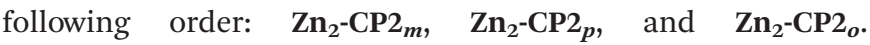
Unexpectedly, the order does not follow the distances between the two zinc porphyrins in $\mathbf{Z n}_{2}-\mathbf{C P} 2_{o}, \mathbf{Z n}_{2}-\mathbf{C P} 2_{m}$, and $\mathbf{Z n}_{2}-\mathbf{C P} 2_{p}$. From the comparison of cyclic zinc porphyrin trimers ${ }^{32}$ and cyclic nickel porphyrin dimers,${ }^{14}$ we expected that a shorter distance between the two zinc porphyrins would be advantageous for longer retention. However, the order of $\mathbf{Z} \mathbf{n}_{2}-\mathbf{C P} \mathbf{2}_{\boldsymbol{m}}$

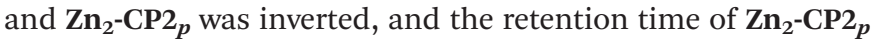
was significantly longer. This result cannot be explained by differences in the static structures prepared by molecular models (Fig. 13). In the ${ }^{1} \mathrm{H}$ NMR analyses, conformational isomers (syn and anti) were present in both $\mathbf{Z n}_{2}-\mathbf{C P} \mathbf{2}_{m}$ and $\mathbf{Z n}_{2}$ $\mathbf{C P} 2_{p}$. The exchange rate between the syn and anti isomers was slower for $\mathbf{Z n}_{2}-\mathbf{C P 2}$. The slower exchange rate was ascribed to the restriction of conformational freedom in $\mathbf{Z n} \mathbf{n}_{\mathbf{2}}-\mathbf{C P} \mathbf{2}_{\boldsymbol{p}}$. Here, we assume that cyanopropyl moieties on the modified silica gel interact with the major syn forms of both $\mathbf{Z n}_{2}-\mathbf{C P} \mathbf{2}_{m}$ and $\mathbf{Z n}_{2}-\mathbf{C P} 2_{p}$, and the retention is determined by the period of the interaction. The period of the interaction depends on the rigidity of the cyclic porphyrins. Thus, $\mathbf{Z n}_{2}-\mathbf{C P} \mathbf{2}_{\boldsymbol{p}}$ is advantageous for longer retention than $\mathbf{Z n}_{\mathbf{2}}-\mathbf{C P} \mathbf{2}_{\boldsymbol{m}}$. In the case of $\mathbf{Z n}_{\mathbf{2}}-\mathbf{C P} \mathbf{2}_{\boldsymbol{o}}$, the close distance between the two porphyrin moieties probably contributes to the significantly longer retention observed in Fig. 5.

This new insight into the mechanism of the unique chromatographic behavior of the CN-MS column was proposed by preparing a series of cyclic porphyrin dimers, $\mathbf{Z n}_{\mathbf{2}}-\mathbf{C P 2} \mathbf{2}_{\boldsymbol{o}}, \mathbf{Z n}_{\mathbf{2}^{-}}$ 


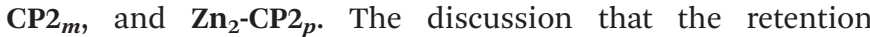
depends on the rigidity of the cyclic porphyrins requires further studies.

\section{Conclusions}

Metal-templated bisamide linking of bis(zinc porphyrin) with two aniline groups connected through 2,2'-bipyridyl at 6,6'positions with phthaloyl dichloride, isophthaloyl dichloride, and terephthaloyl dichloride was accomplished to afford $\mathbf{Z n}_{2}$ $\mathbf{C P} 2_{\boldsymbol{o}}, \mathbf{Z n}_{\mathbf{2}}-\mathbf{C P} \mathbf{2}_{\boldsymbol{m}}$, and $\mathbf{Z n}_{\mathbf{2}}-\mathbf{C P} \mathbf{2}_{\boldsymbol{p}}$. The yields were significantly improved compared to those obtained under metal-free conditions. In particular, phthalimide and terephthalamide derivatives were obtained only by metal-templated synthesis.

Although the target macrocyclic compounds $\mathbf{Z n _ { 2 } - \mathbf { C P 2 }} \mathbf{2}_{\boldsymbol{o}}, \mathbf{Z n}_{\mathbf{2}^{-}}$ $\mathbf{C P} 2_{m}$, and $\mathbf{Z n}_{2}-\mathbf{C P} 2_{p}$ were obtained as mixtures containing significant amounts of linear derivatives, the target compounds were isolated using a preparative CN-MS column using pyridine as an eluent, without any loss during the purification process. This interesting result is because of the specific retention of the cyclic porphyrin compounds on the CN-MS column.

Structural analyses of $\mathbf{Z n}_{2}-\mathbf{C P} 2_{o}, \mathbf{Z n}_{2}-\mathbf{C P} 2_{m}$, and $\mathbf{Z n}_{2}-\mathbf{C P} 2_{p}$ were performed by NMR and UV-vis spectroscopies as well as DFT calculations. In the UV-vis method, populations of conformational isomers and the relative distances and orientations between the two zinc porphyrins in each cyclic porphyrin dimer could be estimated. It was seen that the two porphyrin moieties were twisted in $\mathbf{Z} \mathbf{n}_{\mathbf{2}}-\mathbf{C P} \mathbf{2}_{\boldsymbol{o}}$, whereas they were parallel in $\mathbf{Z} \mathbf{n}_{2}-\mathbf{C P} \mathbf{2}_{m}$. The distances between the two zinc porphyrins were extended in the following order: $\mathbf{Z n _ { 2 } - \mathbf { C P 2 }} \boldsymbol{o}, \mathbf{Z n}_{\mathbf{2}^{-}}$ $\mathbf{C P} 2_{m}$, and $\mathbf{Z n}_{2}-\mathbf{C P} 2_{p}$. This was confirmed by ${ }^{1} \mathrm{H}$ NMR and DFT calculations.

In the NMR methods, exchanges between the conformers in each cyclic porphyrin were observed. The relative exchange

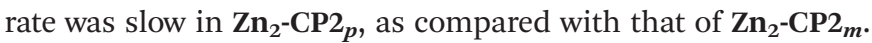
As a result, syn and anti conformers were observed separately in the ${ }^{1} \mathrm{H}$ NMR spectrum of $\mathbf{Z} \mathbf{n}_{\mathbf{2}}-\mathbf{C P} \mathbf{2}_{\boldsymbol{p}}$.

The order of specific retention of the cyclic porphyrins on a CN-MS chromatography column was not followed by the distances between the two zinc porphyrins in $\mathbf{Z n}_{\mathbf{2}}-\mathbf{C P} \mathbf{2}_{\boldsymbol{o}}, \mathbf{Z n}_{\mathbf{2}^{-}}$ $\mathbf{C P} 2_{m}$, and $\mathbf{Z n}_{2}-\mathbf{C P} 2_{p}$. Based on the rigid structure of the tere-

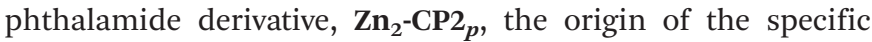
retention on a $\mathrm{CN}-\mathrm{MS}$ chromatography column was attributed to both the distance and rigidity of the cyclic porphyrins.

\section{Experimental}

\section{General procedure}

All chemicals and solvents were of commercial reagent quality and were used without further purification unless otherwise stated. Aldehyde 1, (3-formyl-phenyl)-carbamic acid tert-butyl ester, was prepared according to the literature. ${ }^{33} \mathrm{~N}, \mathrm{~N}$ Dimethylformamide (DMF) was dried over molecular sieves of size $4 \AA$ and distilled under reduced pressure. The reactions were performed on silica gel $60 \mathrm{~F}_{254}$ TLC plates (Merck). The silica gel utilized for column chromatography was purchased from Kanto Chemical Co. Inc.: Silica gel (Spherical, Neutral) 40-100 $\mu \mathrm{m}$ and (Flash) 40-50 $\mu \mathrm{m}$. Cyanopropyl-modified silica gel (CN-MS, Cyanogel) (dp: $40 \mu \mathrm{m}$, pore size: $60 \AA$ A) was purchased from Yamazen, and a mixture of toluene and pyridine $(85 / 15 \mathrm{v} / \mathrm{v})$ and $100 \%$ pyridine were used as eluents. ${ }^{1} \mathrm{H}$ and ${ }^{13} \mathrm{C}$ NMR, distortionless enhancement by polarization transfer 135 (DEPT 135), COSY, HSQC, and NOESY spectra were recorded using a JEOL JNM-ECS-500. Chemical shifts were recorded in parts per million ( $\mathrm{ppm}$ ) relative to tetramethylsilane. MALDI-TOF mass spectra were recorded on a JEOL JMS S-3000 system with dithranol as a matrix with sodium iodide (NaI). UV-vis absorption spectra were collected using a square cell (path length $=1.0 \mathrm{~cm}$ ) on a JASCO V-650 spectrometer. Steady-state emission spectra were collected on a Hitachi F-4500 spectrometer and corrected for the response of the detector system. The fluorescence intensities were normalized at the absorbance of the excitation wavelength.

\section{High-performance liquid chromatographies (HPLCs)}

HPLCs were carried out by using the following three systems: [System 1] JASCO PU-2080plus and MD-2018plus systems equipped with two TSK G2500H $\mathrm{H}_{\mathrm{HR}}$ (Tosoh, $7.8 \mathrm{~mm} \times 30 \mathrm{~cm}$, exclusion limit: $20000 \mathrm{Da}$ ) and one TSK G2000H $\mathrm{H}_{\mathrm{HR}}$ (Tosoh, $7.8 \mathrm{~mm} \times 30 \mathrm{~cm}$, exclusion limit: $10000 \mathrm{Da})$ columns using pyridine as an eluent. [System 2] JASCO PU-2089 and MD-44010 systems equipped with a Cosmosil 5CN-MS column (nacalai tesque, $7.5 \mathrm{~mm}$ I.D. $\times 5 \mathrm{~cm}$ ) using toluene/pyridine $(15 / 85)$ or $100 \%$ pyridine as an eluent. [System 3: Preparative HPLC] LC-908 (JAI) attached to one TSK G2500H $\mathrm{HR}_{\mathrm{HR}}$ column and one $\mathrm{G}_{2} 000 \mathrm{H}_{\mathrm{HR}}$ column eluted with pyridine as an eluent.

\section{Computational methods}

DFT calculations were carried out using the Gaussian 09 package of programs. ${ }^{34}$ Each structure was fully optimized using the B3LYP functional with the 6-31G(d) basis set. The stationary points were verified using vibrational analysis.

\section{Synthesis of $4 \mathrm{Zn}$}

A $500 \mathrm{~mL}$ three-necked round-bottom flask was charged with aldehyde 1 (0.312 g, $1.42 \mathrm{mmol}$ ), 6-bromo-2-pyridinecarboxaldehyde 2 (0.266 g, $1.42 \mathrm{mmol})$, dipyrromethane 3 (0.751 g, $2.84 \mathrm{mmol})$, and Ar-saturated $\mathrm{CHCl}_{3}(285 \mathrm{~mL})$. Then, $1 \mathrm{~mL}$ of $\mathrm{CHCl}_{3}$ solution containing $\mathrm{BF}_{3} \cdot \mathrm{OEt}_{2}(100 \mu \mathrm{L}, 0.796 \mathrm{mmol})$ was slowly added to it, and the mixture was stirred at rt under an Ar atmosphere in the dark. After $0.5 \mathrm{~h}, 1 \mathrm{~mL}$ of $\mathrm{CHCl}_{3}$ solution containing $\mathrm{Et}_{3} \mathrm{~N}(200 \mu \mathrm{L}, 1.59 \mathrm{mmol})$ and $p$-chloranil (1.05 g, $4.26 \mathrm{mmol}$ ) were added to it, and the mixture was stirred at room temperature for $19 \mathrm{~h}$. The solvent was evaporated to dryness. The black-purple residue was purified twice with flush silica gel columns (eluent: $\mathrm{CHCl}_{3}$ ), giving a purple solid containing a symmetric byproduct porphyrin and $\mathbf{4 F b}$ $(0.616 \mathrm{~g})$. The solid was placed in a $100 \mathrm{~mL}$ flask and dissolved in $\mathrm{CHCl}_{3}(20 \mathrm{~mL})$. A small amount $(\sim 1 \mathrm{~mL})$ of methanol con- 
taining $\mathrm{Zn}(\mathrm{OAc})_{2}(0.632 \mathrm{~g}, 3.44 \mathrm{mmol})$ was added to it, and the mixture was stirred for $42 \mathrm{~h}$. The resulting solution was washed with water $(\times 2)$ and brine. The organic layer was dried over anhydrous $\mathrm{Na}_{2} \mathrm{SO}_{4}$ and the solvent was evaporated to dryness. The crude purple solid $(0.625 \mathrm{~g})$ was purified with a flush silica gel column (eluent: toluene: ethyl acetate = $70: 1 \rightarrow 30: 1 \rightarrow 10: 1$ ), giving pure target porphyrin 4Zn $(0.286 \mathrm{~g}, 0.299 \mathrm{mmol})$ with $21 \%$ yield (based on aldehyde $\mathbf{1})$. ${ }^{1} \mathrm{H}$ NMR $\left(400 \mathrm{MHz}, \mathrm{CDCl}_{3}\right) \delta / \mathrm{ppm}=8.87(\mathrm{~d}, J=4.4 \mathrm{~Hz}, 2 \mathrm{H})$, $8.82(\mathrm{~d}, J=4.4 \mathrm{~Hz}, 2 \mathrm{H}), 8.80(\mathrm{~d}, J=4.4 \mathrm{~Hz}, 2 \mathrm{H}), 8.75$ (d, $J=4.4$ $\mathrm{Hz}, 2 \mathrm{H}), 8.25(\mathrm{~d}, J=6.8 \mathrm{~Hz}, 1 \mathrm{H}), 7.94-7.86(\mathrm{~m}, 4 \mathrm{H}), 7.60(\mathrm{~s}$, $1 \mathrm{H}), 7.28(\mathrm{~s}, 4 \mathrm{H}), 2.63(\mathrm{~s}, 6 \mathrm{H}), 1.81(\mathrm{~s}, 12 \mathrm{H}), 1.45(\mathrm{~s}, 9 \mathrm{H}) ;{ }^{13} \mathrm{C}$ NMR $\left(75 \mathrm{MHz}, \mathrm{CDCl}_{3}\right) \delta / \mathrm{ppm}=162.70,150.35,149.99,149.87$, 149.60, 143.48, 140.71, 139.36, 139.04, 137.97, 137.58, 136.81, 132.66, 131.61, 131.51, 130.86, 129.64, 129.13, 128.79, 128.32, $127.75,127.11,126.76,125.39$, 119.69, 117.74, 116.24, 80.91,

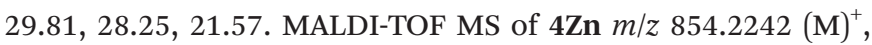
calcd for $\mathrm{C}_{54} \mathrm{H}_{47} \mathrm{BrN}_{6} \mathrm{O}_{2} \mathrm{Zn}$ 854.2232.

\section{Synthesis of $5 \mathrm{Zn}_{2}$}

A $200 \mathrm{~mL}$ Schlenk tube was charged with 4Zn (108 mg, $0.112 \mathrm{mmol}$ ), 2,2'-bipyridine (22.0 $\mathrm{mg}, 0.141 \mathrm{mmol}$ ). After the Schlenk tube was evacuated and filled with Ar gas, dry DMF degassed with freeze-thaw cycles $(100 \mathrm{~mL})$ and 1,5-cyclooctadiene $(42 \mu \mathrm{L}, 0.342 \mathrm{mmol})$ were added to the tube. After the mixture was stirred for $10 \mathrm{~min}$ at room temperature, $\mathrm{Ni}(\mathrm{cod})_{2}$ (960 mg, $3.49 \mathrm{mmol}$ ) was added. The reaction mixture was sonicated and stirred at rt in the dark. After overnight stirring, the resulting mixture was added to a small amount of $\mathrm{CHCl}_{3}$ $(\sim 20 \mathrm{~mL})$ in a perfluoroalkoxy alkane (PFA)-coated flask. The Schlenk tube was washed with $\mathrm{CHCl}_{3}(\sim 20 \mathrm{~mL})$. The combined $\mathrm{CHCl}_{3}$ solution was washed with $0.3 \mathrm{M}$ citric acid solution $(\times 4), 25 \%$ ammonium solution $(\times 3)$, and dried over anhydrous $\mathrm{Na}_{2} \mathrm{SO}_{4}$. The solution was passed through a membrane filter (Omnipore, $0.1 \mu \mathrm{m}$ ) to remove the precipitates. The filtrate was concentrated to dryness, giving a crude purple solid containing $\mathbf{5} \mathbf{Z n}_{\mathbf{2}}$ (110 mg). Retention times of HPLC (columns: TOSOH $\mathrm{G} 2500 \mathrm{H}_{\mathrm{HR}} \times 2+\mathrm{G} 2000 \mathrm{H}_{\mathrm{HR}} \times 1$, eluent: pyridine, flow rate: $1.0 \mathrm{~mL} \mathrm{~min}^{-1}$ ): $21.62 \mathrm{~min}$ for $\mathbf{5} \mathbf{Z n}_{2}$ and $23.68 \mathrm{~min}$ for monomers containing 4Zn. UV-vis absorption of a pure sample obtained by $\mathrm{Zn}$ insertion to a pure $\mathbf{5 F b}_{2}: \lambda_{\max }\left(\mathrm{CHCl}_{3}\right) / \mathrm{nm}=$ $430\left(\varepsilon=6.7 \times 10^{5} \mathrm{M}^{-1} \mathrm{~cm}^{-1}\right)$ and $553\left(\varepsilon=3.4 \times 10^{4} \mathrm{M}^{-1} \mathrm{~cm}^{-1}\right)$. NMR spectroscopic analysis could not be performed due to its poor solubility in any solvent. MALDI-TOF MS of $\mathbf{5 Z n}_{\mathbf{2}}$ $\left(\mathrm{C}_{108} \mathrm{H}_{94} \mathrm{~N}_{12} \mathrm{O}_{4} \mathrm{Zn}_{2}\right.$, exact $\left.\mathrm{MS} 1750.61\right)$ gave only fragment signals corresponding to de-Boc derivatives: $\mathrm{m} / \mathrm{z} 1551.49\left(\mathbf{5} \mathbf{Z n}_{\mathbf{2}}\right.$ - $\left.(\mathrm{Boc})_{2}+(\mathrm{H})_{3}\right)^{+}$, calcd for $\mathrm{C}_{98} \mathrm{H}_{78} \mathrm{~N}_{12} \mathrm{Zn}_{2}$ 1551.51.

\section{Synthesis of $5 \mathrm{Fb}_{2}$}

A $20 \mathrm{~mL}$ flask was charged with a crude purple solid containing $\mathbf{5 Z n}_{2}(110 \mathrm{mg})$ and $\mathrm{CHCl}_{3}(20 \mathrm{~mL})$. Trifluoroacetic acid (TFA) (0.1 mL, $1.31 \mathrm{mmol})$ was slowly added to it and the mixture was stirred at $\mathrm{rt}$ for $1.5 \mathrm{~h}$. The resulting solution was slowly poured into a saturated $\mathrm{NaHCO}_{3}$ aqueous solution $(50 \mathrm{~mL})$ in an ice-bath. The organic layer was transferred into a PFA-coated funnel and the aqueous layer was extracted with
$\mathrm{CHCl}_{3}(10 \mathrm{~mL} \times 3)$. The combined organic layer was washed with water and dried over anhydrous $\mathrm{Na}_{2} \mathrm{SO}_{4}$. The solution was passed through a membrane filter (Omnipore, $0.1 \mu \mathrm{m}$ ) to remove the precipitates, and the filtrate was concentrated to dryness. The resulting residue was purified with a preparative HPLC using pyridine as an eluent, giving a purple solid, $\mathbf{5} \mathbf{F b}_{\mathbf{2}}$ (57.8 mg, $35.5 \mu \mathrm{mol}$ ) in 69\% yield (2 steps from $4 \mathrm{Zn}$ ). ${ }^{1} \mathrm{H}$ NMR $\left(400 \mathrm{MHz}, \mathrm{CDCl}_{3}\right) \delta / \mathrm{ppm}=9.02-9.00(\mathrm{~m}, 6 \mathrm{H}), 8.86(\mathrm{~d}, J=4.0$ $\mathrm{Hz}, 4 \mathrm{H}), 8.79$ (d, $J=4.0 \mathrm{~Hz}, 4 \mathrm{H}), 8.72(\mathrm{~d}, J=4.0 \mathrm{~Hz}, 4 \mathrm{H}), 8.26$ $(\mathrm{d}, J=4.0 \mathrm{~Hz}, 2 \mathrm{H}), 8.11(\mathrm{t}, J=6.8 \mathrm{~Hz}, 4 \mathrm{H}), 7.96(\mathrm{~s}, 4 \mathrm{H}), 7.67(\mathrm{t}, J$ $=6.8 \mathrm{~Hz}, 2 \mathrm{H}), 7.30(\mathrm{~s}, 8 \mathrm{H}), 6.76(\mathrm{~s}, 2 \mathrm{H}), 2.64(\mathrm{~s}, 12 \mathrm{H}), 1.88(\mathrm{~s}$, $24 \mathrm{H}), 1.53(\mathrm{~s}, 18 \mathrm{H}),-2.53(\mathrm{~s}, 4 \mathrm{H}) ;{ }^{13} \mathrm{C} \mathrm{NMR}\left(75 \mathrm{MHz}, \mathrm{CDCl}_{3}\right) \delta /$ $\mathrm{ppm}=160.19,155.37,153.13,142.87,139.55,138.57,137.89$, $137.00,135.90,130.63$, 129.74, 127.92, 127.44, 124.86, 123.89, $120.46,119.48,118.62,118.03$, 117.74, 80.86, 28.52, 21.82, 21.62. MALDI-TOF MS of $\mathbf{5 F b}_{2} \quad\left(\mathrm{C}_{108} \mathrm{H}_{98} \mathrm{~N}_{12} \mathrm{O}_{4}\right.$; $\mathrm{C}_{108} \mathrm{H}_{94} \mathrm{~N}_{12} \mathrm{O}_{4} \mathrm{Zn}_{2}$, exact MS 1626.78) gave only fragment signals corresponding to $\left[\mathbf{5} \mathbf{F b}_{\mathbf{2}}-(\mathrm{Boc})-(t \text {-butoxy })+(\mathrm{H})_{2}\right]^{+}(\mathrm{m} /$ $z$ 1454.70) and $\left[\mathbf{5 F b}_{2}-(\mathrm{Boc})_{2}+(\mathrm{H})_{2}\right]^{+}(\mathrm{m} / z$ 1426.68).

\section{Synthesis of $6 \mathrm{Fb}_{2}$}

TFA $(2.0 \mathrm{~mL})$ was slowly added to $\mathbf{5} \mathbf{F b}_{\mathbf{2}}(26.5 \mathrm{mg}, 16.3 \mu \mathrm{mol})$ in a $25 \mathrm{~mL}$ flask, and the mixture was stirred for $1 \mathrm{~h}$. The resulting solution was slowly poured into a saturated $\mathrm{NaHCO}_{3}$ aqueous solution $(50 \mathrm{~mL})$ in an ice-bath. The organic layer was transferred to a PFA-coated funnel and the aqueous layer was extracted with $\mathrm{CHCl}_{3}(10 \mathrm{~mL} \times 3)$. The combined organic layer was washed with water and dried over anhydrous $\mathrm{Na}_{2} \mathrm{SO}_{4}$. The solvent was evaporated to dryness, giving a purple solid $\mathbf{6} \mathbf{F b}_{\mathbf{2}}$ (22.0 mg). TLC (toluene: EtOAc $=30: 1) R_{\mathrm{f}}=0.50 ;{ }^{1} \mathrm{H}$ NMR $\left(400 \mathrm{MHz}, \mathrm{CDCl}_{3}\right) \delta / \mathrm{ppm}=8.99-9.03(\mathrm{~m}, 6 \mathrm{H}), 8.93(\mathrm{~d}, J=4.4$ $\mathrm{Hz}, 4 \mathrm{H}), 8.79$ (d, $J=4.4 \mathrm{~Hz}, 4 \mathrm{H}), 8.72(\mathrm{~d}, J=4.4 \mathrm{~Hz}, 4 \mathrm{H}), 8.25$ $(\mathrm{d}, J=7.8 \mathrm{~Hz}, 2 \mathrm{H}), 8.12(\mathrm{t}, J=7.8 \mathrm{~Hz}, 2 \mathrm{H}), 7.75-7.40(\mathrm{~m}(\mathrm{br})$, $6 \mathrm{H}), 7.31(\mathrm{~s}, 8 \mathrm{H}), 7.10(\mathrm{~d}, J=7.8 \mathrm{~Hz}, 2 \mathrm{H}), 2.65(\mathrm{~s}, 12 \mathrm{H}), 1.89(\mathrm{~s}$, $24 \mathrm{H}),-2.53$ (s, 4H); UV-vis absorption: $\lambda_{\max }\left(\mathrm{CHCl}_{3}\right) / \mathrm{nm}=425$, $516,551,589$; fluorescence $\left(\lambda_{\mathrm{ex}}=515 \mathrm{~nm}, \mathrm{CHCl}_{3}\right): \lambda_{\max } / \mathrm{nm}=$ 648, 713. MALDI-TOF MS of $6 \mathbf{F b}_{2}\left(\mathrm{C}_{98} \mathrm{H}_{82} \mathrm{~N}_{12}\right.$; M.W. 1427.8): found $m / z 1428.0(\mathbf{M})^{+}$.

\section{Synthesis of $6 \mathrm{Zn}_{2}$}

A $20 \mathrm{~mL}$ flask was charged with $\mathbf{6} \mathbf{F b}_{2}(22.0 \mathrm{mg})$ and $\mathrm{CHCl}_{3}$ (5 mL). $\mathrm{Zn}(\mathrm{OAc})_{2}(56.8 \mathrm{mg}, 310 \mu \mathrm{mol})$ in a small amount of methanol $(\sim 1 \mathrm{~mL})$ was added to it and the mixture was stirred at $\mathrm{rt}$ for $19 \mathrm{~h}$. The resulting solution was transferred to a PFAcoated funnel and washed with water $(\times 2)$ and brine. The organic layer was passed through Phase Separator paper (Whatman). The solvent was evaporated to dryness, giving a purple solid $\mathbf{6 Z n _ { 2 }}(28.3 \mathrm{mg}, 18.2 \mu \mathrm{mol})$ quantitatively from $\mathbf{5 F b}_{2}$. TLC (toluene $:$ EtOAc $=30: 1$ ) $R_{\mathrm{f}}=0.13$; UV-vis absorption: $\lambda_{\max }\left(\mathrm{CHCl}_{3}\right) / \mathrm{nm}=423,559,600$; fluorescence $\left(\lambda_{\mathrm{ex}}=\right.$ $\left.515 \mathrm{~nm}, \mathrm{CHCl}_{3}\right) \lambda_{\text {max }} / \mathrm{nm}=607,651$. NMR spectroscopic analysis could not be performed due to the poor solubility in any solvent. MALDI-TOF MS of $\mathbf{6 Z n}_{2} \mathrm{~m} / z 1551.50(\mathrm{M}+\mathrm{H})^{+}$, calcd for $\mathrm{C}_{98} \mathrm{H}_{79} \mathrm{~N}_{12} \mathrm{Zn}_{2}$ 1551.51. 


\section{Synthesis of $\mathrm{Zn}_{2}-\mathrm{CP} 2_{o, m, p}$ (metal templated synthesis)}

A $10 \mathrm{~mL}$ flask was charged with $6 \mathbf{Z n}_{2}(5.0 \mathrm{mg}, 3.2 \mu \mathrm{mol})$ and dry $\mathrm{CH}_{2} \mathrm{Cl}_{2}(5 \mathrm{~mL})$. A $\mathrm{CH}_{3} \mathrm{CN}(\sim 1 \mathrm{~mL})$ solution containing the metal ion $(3.2 \mu \mathrm{mol})$ was slowly added to it, and the resulting solution was transferred to a $300 \mathrm{~mL}$ three-necked round bottom flask and diluted with dry $\mathrm{CH}_{2} \mathrm{Cl}_{2}$ to be $0.2 \mathrm{mM}$ of 6Zn 2 . A dry $\mathrm{CH}_{2} \mathrm{Cl}_{2}$ solution $(5 \mathrm{~mL}$ ) containing dichloride $(4.8 \mu \mathrm{mol})$ and pyridine $(1 \mu \mathrm{L}, 12 \mu \mathrm{mol})$ was slowly added to the $6 \mathbf{Z n}_{2}$ solution for $12 \mathrm{~h}$ with a microsyringe pump (KD Scientific, KDS 100). The solution was poured into a saturated $\mathrm{NaHCO}_{3}$ aqueous solution $(50 \mathrm{~mL})$ in a PFA-coated flask. The organic layer was washed with water $(\times 3)$, and passed through Phase Separator paper (Whatman). The solvent was evaporated to dryness, giving a purple solid. The solids obtained by the reactions with three kinds of dichlorides were analyzed with HPLCs to estimate the reaction yields.

\section{Purification of $\mathrm{Zn}_{2}-\mathrm{CP} 2_{o, m, p}$}

The crude mixtures containing the target cyclic dimers were purified on cyanopropyl modified silica gel columns (YFLC Gel, CN, Yamazene Co. pore size: $40 \mu \mathrm{m}$ ) with a mixed solvent of toluene and pyridine (15/85 v/v) and $100 \%$ pyridine as an eluent. The solvent was evaporated to dryness, giving pure target products.

$\mathbf{Z n}_{2}-\mathbf{C P 2}{ }_{o}{ }^{1} \mathrm{H}$ NMR $\left(500 \mathrm{MHz}\right.$, pyridine- $\left.d_{5}\right) \delta / \mathrm{ppm}=11.59(\mathrm{~s}$, $2 \mathrm{H}), 9.05(\mathrm{~s}, 2 \mathrm{H}), 8.73(\mathrm{~s}, 4 \mathrm{H}), 8.64(\mathrm{~s}, 4 \mathrm{H}), 8.45-8.42(8 \mathrm{H}), 8.28$ $(\mathrm{t}, J=8.0 \mathrm{~Hz}, 2 \mathrm{H}), 8.06-7.91(\mathrm{~m}, 4 \mathrm{H}), 7.72(\mathrm{t}, J=7.8 \mathrm{~Hz}, 2 \mathrm{H})$, $7.36(\mathrm{~s}, 8 \mathrm{H}), 7.11(\mathrm{~s}, 4 \mathrm{H}), 2.53(\mathrm{~s}, 12 \mathrm{H}), 1.79(\mathrm{~s}, 12 \mathrm{H}), 1.50$ (s, 12H); MALDI-TOF-MS (dithranol) $\mathrm{m} / \mathrm{z} 1680.4970(\mathrm{M})^{+}$, calcd for $\left[\mathrm{C}_{106} \mathrm{H}_{81} \mathrm{~N}_{12} \mathrm{O}_{2} \mathrm{Zn}_{2}\right]^{+} 1680.5110$.

$\mathbf{Z n}_{2}-\mathbf{C P} 2_{m}{ }^{1} \mathrm{H}$ and ${ }^{13} \mathrm{C}$ NMR assignments are shown in Fig. S23. $\dagger$ MALDI-TOF-MS (dithranol) $m / z 1681.5197(\mathbf{M}+\mathrm{H})^{+}$, calcd for $\left[\mathrm{C}_{106} \mathrm{H}_{81} \mathrm{~N}_{12} \mathrm{O}_{2} \mathrm{Zn}_{2}\right]^{+} 1681.5183$.

$\mathbf{Z n}_{2}-\mathbf{C P} 2{ }^{1}{ }^{1} \mathrm{H}$ and ${ }^{13} \mathrm{C}$ NMR assignments are shown in Fig. S31. $\dagger$ MALDI-TOF-MS (dithranol) $\mathrm{m} / \mathrm{z} 1703.4968(\mathrm{M}+\mathrm{Na})^{+}$, calcd for $\left[\mathrm{C}_{106} \mathrm{H}_{80} \mathrm{~N}_{12} \mathrm{O}_{2} \mathrm{Zn}_{2} \mathrm{Na}\right]^{+}$1703.5003.

\section{Synthesis of $7 \mathbf{F b}$}

TFA $(4.0 \mathrm{~mL})$ was slowly added to $4 \mathrm{Zn}(50.4 \mathrm{mg}, 52.7 \mu \mathrm{mol})$ in a $25 \mathrm{~mL}$ flask, and the mixture was stirred at $\mathrm{rt}$ for $1 \mathrm{~h}$. The resulting solution was poured into a saturated $\mathrm{NaHCO}_{3}$ aqueous solution $(50 \mathrm{~mL})$ in an ice-bath. The organic layer was transferred to a PFA-coated funnel and the aqueous layer was extracted with $\mathrm{CHCl}_{3}(10 \mathrm{~mL} \times 3)$. The combined organic layer was washed with water and dried over anhydrous $\mathrm{Na}_{2} \mathrm{SO}_{4}$. The solvent was evaporated to dryness, giving a purple solid 7Fb $(37.7 \mathrm{mg}, 47.5 \mu \mathrm{mol})$ in $91 \%$ yield. ${ }^{1} \mathrm{H}$ NMR $(400 \mathrm{MHz}$, $\left.\mathrm{CDCl}_{3}\right) \delta / \mathrm{ppm}=8.89(\mathrm{~d}, J=4.8 \mathrm{~Hz}, 2 \mathrm{H}), 8.78(\mathrm{~d}, J=4.8 \mathrm{~Hz}$, $2 \mathrm{H}), 8.72(\mathrm{~d}, J=4.8 \mathrm{~Hz}, 2 \mathrm{H}), 8.67$ (d, $J=4.8 \mathrm{~Hz}, 2 \mathrm{H}), 8.25$ (dd, $J=6.4,2.0 \mathrm{~Hz}, 1 \mathrm{H}), 7.91-7.86(\mathrm{~m}, 2 \mathrm{H}), 7.61(\mathrm{~d}, J=7.8 \mathrm{~Hz}, 2 \mathrm{H})$, $7.54(\mathrm{~s}, 1 \mathrm{H}), 7.47(\mathrm{t}, J=7.8 \mathrm{~Hz}, 1 \mathrm{H}), 7.27(\mathrm{~s}, 4 \mathrm{H}), 7.05(\mathrm{~m}$, 1H), 3.92 (s (br), 2H), 2.62 (s, 6H), $1.82(\mathrm{~s}, 12 \mathrm{H}),-2.65(\mathrm{~s}, 2 \mathrm{H})$. MALDI-TOF MS of $7 \mathbf{F b} \mathrm{m} / \mathrm{z} 792.24(\mathrm{M})^{+}$, calcd for $\mathrm{C}_{49} \mathrm{H}_{41} \mathrm{BrN}_{6}$ 792.26 .

\section{Synthesis of $\mathbf{8 F b _ { 2 }}$}

A $50 \mathrm{~mL}$ two-necked flask was charged with $7 \mathbf{F b}(17.1 \mathrm{mg}$, $21.5 \mu \mathrm{mol}$ ), 4-dimethyl-aminopyridine (DMAP, $2.8 \mathrm{mg}$, $22.9 \mu \mathrm{mol})$ and dry pyridine $(2 \mathrm{~mL})$. A dry $\mathrm{CH}_{2} \mathrm{Cl}_{2}$ solution (4 mL) containing isophthaloyl chloride $(3.2 \mathrm{mg}, 15.8 \mu \mathrm{mol})$ was slowly added to the $7 \mathbf{F b}$ solution with a microsyringe pump (kd Scientific, KDS 100). After $15.5 \mathrm{~h}$, the solution was poured into a saturated $\mathrm{NaHCO}_{3}$ aqueous solution in a PFAcoated flask. The organic layer was washed with water $(\times 3)$, and passed through Phase Separator paper (Whatman). The solvent was evaporated to dryness, giving a purple solid (16.6 mg). The crude solid was purified with a flush silica gel column (eluent: $\mathrm{CHCl}_{3}$ ), affording a pure target compound $\mathbf{8 F b}_{2}(7.8 \mathrm{mg}, 4.5 \mu \mathrm{mol})$ in $42 \%$ yield. TLC $\left(\mathrm{CHCl}_{3}: \mathrm{MeOH}=\right.$ $50: 1) R_{\mathrm{f}}=0.63 ;{ }^{1} \mathrm{H}$ NMR $\left(400 \mathrm{MHz}, \mathrm{CDCl}_{3}\right) \delta / \mathrm{ppm}=8.81(\mathrm{~d}, J=$ $4.8 \mathrm{~Hz}, 4 \mathrm{H}), 8.78(\mathrm{~d}, J=4.8 \mathrm{~Hz}, 4 \mathrm{H}), 8.71(\mathrm{~d}, J=4.8 \mathrm{~Hz}, 4 \mathrm{H})$, $8.66(\mathrm{~d}, J=4.8 \mathrm{~Hz}, 4 \mathrm{H}), 8.49(\mathrm{~s}, 1 \mathrm{H}), 8.34(\mathrm{~s}, 2 \mathrm{H}), 8.21(\mathrm{~s}, 1 \mathrm{H})$, 8.15 (dd, $J=8.0,1.2 \mathrm{~Hz}, 2 \mathrm{H}), 8.01-7.87$ (m, 8H), 7.71-7.67 (m, 2H), 7.51-7.41 (m, 2H), $7.25(\mathrm{~s}, 4 \mathrm{H}), 7.21(\mathrm{~s}, 4 \mathrm{H}), 2.59(\mathrm{~s}, 12 \mathrm{H})$, $1.81(\mathrm{~s}, 12 \mathrm{H}), 1.76(\mathrm{~s}, 12 \mathrm{H}),-2.68(\mathrm{~s}, 4 \mathrm{H})$; MALDI-TOF-MS (dithranol) $m / z \quad 1715.5282 \quad(\mathrm{M}+\mathrm{H})^{+}$, calcd for $\left[\mathrm{C}_{106} \mathrm{H}_{85} \mathrm{Br}_{2} \mathrm{~N}_{12} \mathrm{O}_{2}\right]^{+}$1715.5285; UVvis absorption: $\lambda_{\max }\left(\mathrm{CHCl}_{3}\right) /$ $\mathrm{nm}=420,517$.

\section{Synthesis of $8 \mathrm{Zn}_{2}$}

A $10 \mathrm{~mL}$ flask was charged with $\mathbf{8 F b _ { 2 }}(7.8 \mathrm{mg}, 4.5 \mu \mathrm{mol})$ and $\mathrm{CHCl}_{3}(3 \mathrm{~mL}) . \mathrm{Zn}(\mathrm{OAc})_{2}(8.2 \mathrm{mg}, 45 \mu \mathrm{mol})$ in a small amount of methanol was added to it and the mixture was stirred at room temperature for $5 \mathrm{~h}$. The resulting solution was transferred to a PFA-coated funnel and washed with water $(\times 3)$. The organic layer was passed through Phase Separator paper (Whatman). The solvent was evaporated to dryness, giving a purple solid $\mathbf{8 Z n}_{2}(8.0 \mathrm{mg}, 4.3 \mu \mathrm{mol})$ in $96 \%$ yield. TLC $\left(\mathrm{CHCl}_{3}: \mathrm{MeOH}=50: 1\right) R_{\mathrm{f}}=0.13$; UV-vis absorption: $\lambda_{\max }$ $\left(\mathrm{CHCl}_{3}\right) / \mathrm{nm}=426$, 554. MALDI-TOF MS of $\mathbf{8 Z n}_{2} \mathrm{~m} / \mathrm{z} 1838.34$ $(\mathrm{M})^{+}$, calcd for $\mathrm{C}_{106} \mathrm{H}_{80} \mathrm{Br}_{2} \mathrm{~N}_{12} \mathrm{O}_{2} \mathrm{Zn}_{2}$ 1838.35.

\section{Synthesis of $\mathrm{Zn}_{2}-\mathrm{CP} 2_{m}$ (coupling)}

A $20 \mathrm{~mL}$ Schlenk tube was charged with $\mathbf{8 Z n}_{2}(3.0 \mathrm{mg}$, $1.6 \mu \mathrm{mol})$ and 2,2'-bipyridine (0.3 $\mathrm{mg}, 1.9 \mu \mathrm{mol})$. After the Schlenk tube was evacuated and filled with Ar gas, dry DMF degassed with freeze-thaw cycles $(10 \mathrm{~mL})$ and 1,5-cyclooctadiene $(0.6 \mu \mathrm{L}, 1.9 \mu \mathrm{mol})$ were added to the tube. After the mixture was stirred for $10 \mathrm{~min}$ at $\mathrm{rt}, \mathrm{Ni}(\operatorname{cod})_{2}(32.7 \mathrm{mg}$, $119 \mu \mathrm{mol})$ was added. The reaction mixture was sonicated and stirred at $50{ }^{\circ} \mathrm{C}$ in the dark. After overnight stirring, the resulting mixture was added to a small amount of $\mathrm{CHCl}_{3}$ in a perfluoroalkoxy alkane (PFA)-coated flask. The Schlenk tube was washed with $\mathrm{CHCl}_{3}$. The combined $\mathrm{CHCl}_{3}$ solution was washed with $0.3 \mathrm{M}$ citric acid solution $(\times 4)$ and $25 \%$ ammonium solution $(\times 3)$, and dried over anhydrous $\mathrm{Na}_{2} \mathrm{SO}_{4}$. The solution was passed through a membrane filter (Omnipore, $0.1 \mu \mathrm{m}$ ) to remove the precipitates. The filtrate was concentrated to dryness, giving a purple solid $(3.5 \mathrm{mg})$. The solid was analyzed by HPLC to estimate the reaction yield. 


\section{Conflicts of interest}

There are no conflicts to declare.

\section{Acknowledgements}

This work was supported by the ENEOS Hydrogen Trust Fund. We would like to thank Editage for English language editing and the Tokyo University of Science for financial support.

\section{Notes and references}

1 V. V. Borovkov, J. M. Lintuluoto and Y. Inoue, J. Am. Chem. Soc., 2001, 123, 2979-2989.

2 T. Kurtán, N. Nesnas, Y.-Q. Li, X. Huang, K. Nakanishi and N. Berova, J. Am. Chem. Soc., 2001, 123, 5962-5973.

3 V. Valderrey, G. Aragay and P. Ballester, Coord. Chem. Rev., 2014, 258-259, 137-156.

4 K. Kinjo, T. Hirao, S.-I. Kihara, Y. Katsumoto and T. Haino, Angew. Chem., Int. Ed., 2015, 54, 14830-14834.

5 Z. N. Zahran, E. A. Mohamed, A. A. Haleem and Y. Naruta, Chem. - Eur. J., 2018, 24, 10606-10611.

6 J. Rosenthal, B. J. Pistorio, L. L. Chng and D. G. Nocera, J. Org. Chem., 2005, 70, 1885-1888.

7 R. K. Totten, P. Ryan, B. Kang, S. J. Lee, L. J. Broadbelt, R. Q. Snurr, J. T. Hupp and S. T. Nguyen, Chem. Commun., 2012, 48, 4178-4180.

8 P. Mondal, S. Sarkar and S. P. Rath, Chem. - Eur. J., 2017, 23, 7093-7103.

9 P. D. Harvey, C. Stern, C. P. Gros and R. Guilard, Coord. Chem. Rev., 2007, 251, 401-428.

10 A. Satake and Y. Kobuke, Org. Biomol. Chem., 2007, 5, 16791691.

11 S. Durot, J. Taesch and V. Heitz, Chem. Rev., 2014, 114, 8542-8578.

12 Y. Tomohiro, A. Satake and Y. Kobuke, J. Org. Chem., 2001, 66, 8442-8446.

13 S. Fukuda, A. Satake and Y. Kobuke, Thin Solid Films, 2006, 499, 263-268.

14 A. Satake, Y. Katagami, Y. Odaka, Y. Kuramochi, S. Harada, T. Kouchi, H. Kamebuchi and M. Tadokoro, Inorg. Chem., 2020, 59, 8013-8024.

15 S. Fukuzumi, T. Kishi, H. Kotani, Y.-M. Lee and W. Nam, Nat. Chem., 2011, 3, 38-41.

16 S. Funyu, T. Isobe, S. Takagi, D. A. Tryk and H. Inoue, J. Am. Chem. Soc., 2003, 125, 5734-5740.

17 (a) H. Rao, L. C. Schmidt, J. Bonin and M. Robert, Nature, 2017, 548, 74-77; (b) J. Bonin, M. Robert and M. Routier, J. Am. Chem. Soc., 2014, 136, 16768-16771.

18 (a) A. Call, M. Cibian, K. Yamamoto, T. Nakazono, K. Yamauchi and K. Sakai, ACS Catal., 2019, 9, 4867-4874; (b) D. Behar, T. Dhanasekaran, P. Neta, C. M. Hosten, D. Ejeh, P. Hambright and E. Fujita, J. Phys. Chem. A, 1998, 102, 5870-2877.
19 (a) E. A. Mohamed, Z. N. Zahran and Y. Naruta, Chem. Mater., 2017, 29, 7140-7150; (b) E. A. Mohamed, Z. N. Zahran and Y. Naruta, Chem. Commun., 2015, 51, 16900-16903.

20 J. Rosenthal, T. D. Luckett, J. M. Hodgkiss and D. G. Nocera, J. Am. Chem. Soc., 2006, 128, 6546-6547.

21 E. Vanover, Y. Huang, L. Xu, M. Newcomb and R. Zhang, Org. Lett., 2010, 12, 2246-2249.

22 (a) T. Nakazono, A. R. Parent and K. Sakai, Chem. - Eur. J., 2015, 21, 6723-6726; (b) T. Nakazono, A. R. Parent and K. Sakai, Chem. Commun., 2013, 49, 6325-6327.

23 V. Bizet, L. Buglioni and C. Bolm, Angew. Chem., Int. Ed., 2014, 53, 5639-5642.

24 (a) S. Y. Lee, H. S. Fung, S. Feng and K. S. Chan, Organometallics, 2016, 35, 2480-2487; (b) S. Y. Lee and K. S. Chan, Organometallics, 2013, 32, 5391-5401.

25 K. Rybicka-Jasińska, W. Shan, K. Zawada, K. M. Kadish and D. Gryko, J. Am. Chem. Soc., 2016, 138, 15451-15458.

26 S. Shanmugam, J. Xu and C. Boyer, J. Am. Chem. Soc., 2015, 137, 9174-9185.

27 T. Lazarides, L. V. Sazanovich, A. J. Simaan, M. C. Kafentzi, M. Delor, Y. Mekmouche, B. Faure, M. Reglier, J. A. Weinstein, A. G. Coutsolelos and T. Tron, J. Am. Chem. Soc., 2013, 135, 3095-3103.

28 (a) P. Lang, M. Pfrunder, G. Quach, B. Braun-Cula, E. G. Moore and M. Schwalbe, Chem. - Eur. J., 2019, 25, 4509-4519; (b) C. D. Windle, M. W. George, R. N. Perutz, P. A. Summers, X. Z. Sun and A. C. Whitwood, Chem. Sci., 2015, 6, 6847-6864; (c) K. Kiyosawa, N. Shiraishi, T. Shimada, D. Masui, H. Tachibana, S. Takagi, O. Ishitani, D. A. Tryk and H. Inoue, J. Phys. Chem. C, 2009, 113, 11667-11673.

29 (a) Y. Kuramochi, Y. Fujisawa and A. Satake, J. Am. Chem. Soc., 2020, 142, 705-709; (b) Y. Kuramochi and A. Satake, Chem. - Eur. J., 2020, 26, 16365-16373.

30 M. Kasha, Radiat. Res., 1963, 20, 55-70.

31 A. Osuka and K. Maruyama, J. Am. Chem. Soc., 1988, 110, 4454-4456.

32 Y. Ohkoda, A. Asaishi, T. Namiki, T. Hashimoto, M. Yamada, K. Shirai, Y. Katagami, T. Sugaya, M. Tadokoro and A. Satake, Chem. - Eur. J., 2015, 21, 11745-11756.

33 (a) J. M. Hooker, A. Datta, M. Botta, K. N. Raymond and M. B. Francis, Nano Lett., 2007, 7, 2207-2210; (b) T. Schadendorf, C. Hoppmann and K. Rück-Braun, Tetrahedron Lett., 2007, 48, 9044-9047.

34 M. J. Frisch, G. W. Trucks, H. B. Schlegel, G. E. Scuseria, M. A. Robb, J. R. Cheeseman, G. Scalmani, V. Barone, B. Mennucci, G. A. Petersson, H. Nakatsuji, M. Caricato, X. Li, H. P. Hratchian, A. F. Izmaylov, J. Bloino, G. Zheng, J. L. Sonnenberg, M. Hada, M. Ehara, K. Toyota, R. Fukuda, J. Hasegawa, M. Ishida, T. Nakajima, Y. Honda, O. Kitao, H. Nakai, T. Vreven, J. A. Montgomery Jr., J. E. Peralta, F. Ogliaro, M. Bearpark, J. J. Heyd, E. Brothers, K. N. Kudin, V. N. Staroverov, R. Kobayashi, J. Normand, K. Raghavachari, A. Rendell, J. C. Burant, S. S. Iyengar, J. Tomasi, M. Cossi, N. Rega, J. M. Millam, M. Klene, 
J. E. Knox, J. B. Cross, V. Bakken, C. Adamo, J. Jaramillo, R. Gomperts, R. E. Stratmann, O. Yazyev, A. J. Austin, R. Cammi, C. Pomelli, J. W. Ochterski, R. L. Martin, K. Morokuma, V. G. Zakrzewski, G. A. Voth, P. Salvador,
J. J. Dannenberg, S. Dapprich, A. D. Daniels, O. Farkas, J. B. Foresman, J. V. Ortiz, J. Cioslowski and D. J. Fox, Gaussian 09, Revision A.1, Gaussian, Inc., Wallingford CT, 2009. 